\title{
Aerosol backscatter profiles from ceilometers: validation of water vapor correction in the framework of CeiLinEx2015
}

\author{
Matthias Wiegner $^{1}$, Ina Mattis ${ }^{2}$, Margit Pattantyús-Ábrahám ${ }^{2, a}, J^{\prime}$ Juan Antonio Bravo-Aranda ${ }^{3, b}$, Yann Poltera ${ }^{4, c}$, \\ Alexander Haefele ${ }^{4}$, Maxime Hervo ${ }^{4}$, Ulrich Görsdorf ${ }^{5}$, Ronny Leinweber ${ }^{5}$, Josef Gasteiger ${ }^{6}$, Martial Haeffelin $^{3}$, \\ Frank Wagner $^{2, d}$, Jan Cermak ${ }^{7, \mathrm{e}, \mathrm{f}}$, Katerina Komínková ${ }^{8}$, Mike Brettle ${ }^{9}$, Christoph Münkel ${ }^{10}$, and Kornelia Pönitz ${ }^{11}$ \\ ${ }^{1}$ Meteorologisches Institut, Ludwig-Maximilians-Universität, Theresienstraße 37, 80333 München, Germany \\ ${ }^{2}$ Deutscher Wetterdienst, Meteorologisches Observatorium Hohenpeißenberg, Hohenpeißenberg, Germany \\ ${ }^{3}$ Institut Pierre Simon Laplace, École Polytechnique, CNRS, Université Paris-Saclay, Palaiseau, France \\ ${ }^{4}$ MeteoSwiss, Payerne, Switzerland \\ ${ }^{5}$ Deutscher Wetterdienst, Meteorologisches Observatorium Lindenberg, Lindenberg, Germany \\ ${ }^{6}$ Faculty of Physics, University of Vienna, Vienna, Austria \\ ${ }^{7}$ Department of Geography, Ruhr-Universität Bochum, Bochum, Germany \\ ${ }^{8}$ Global Change Research Institute, Czech Academy of Sciences, Brno, Czech Republic \\ ${ }^{9}$ Chartered Meteorologist: Shepshed, UK \\ ${ }^{10}$ Vaisala GmbH, Hamburg, Germany \\ ${ }^{11}$ G. Lufft Mess- und Regeltechnik GmbH, Fellbach, Germany \\ ${ }^{a}$ now at: Federal Office for Radiation Protection, Department of Environmental Radiation, Neuherberg, Germany \\ ${ }^{b}$ now at: University of Granada, Granada, Spain \\ ${ }^{c}$ now at: Institute for Atmospheric and Climate Science, ETH Zurich, Zurich, Switzerland \\ ${ }^{d}$ now at: Karlsruhe Institute of Technology (KIT), IMK-TRO, Eggenstein-Leopoldshafen, Germany \\ ${ }^{e}$ now at: Karlsruhe Institute of Technology (KIT), Institute of Meteorology and Climate Research, Karlsruhe, Germany

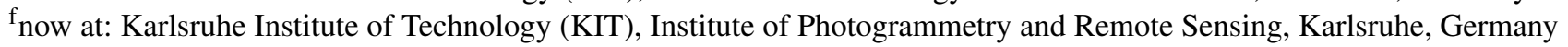

Correspondence: Matthias Wiegner (m.wiegner@lmu.de)

Received: 11 September 2018 - Discussion started: 17 October 2018

Revised: 10 January 2019 - Accepted: 15 January 2019 - Published: 25 January 2019

\begin{abstract}
With the rapidly growing number of automated single-wavelength backscatter lidars (ceilometers), their potential benefit for aerosol remote sensing received considerable scientific attention. When studying the accuracy of retrieved particle backscatter coefficients, it must be considered that most of the ceilometers are influenced by water vapor absorption in the spectral range around $910 \mathrm{~nm}$. In the literature methodologies have been proposed to correct for this effect; however, a validation was not yet performed. In the framework of the ceilometer intercomparison campaign CeiLinEx2015 in Lindenberg, Germany, hosted by the German Weather Service, it was possible to tackle this open issue. Ceilometers from Lufft (CHM15k and CHM15kx, operating at $1064 \mathrm{~nm}$ ), from Vaisala (CL51 and CL31) and from Campbell Scientific (CS135), all operating at a wavelength of
\end{abstract}

approximately $910 \mathrm{~nm}$, were deployed together with a multiwavelength research lidar (RALPH) that served as a reference. In this paper the validation of the water vapor correction is performed by comparing ceilometer backscatter signals with measurements of the reference system extrapolated to the water vapor regime. One inherent problem of the validation is the spectral extrapolation of particle optical properties. For this purpose AERONET measurements and inversions of RALPH signals were used. Another issue is that the vertical range where validation is possible is limited to the upper part of the mixing layer due to incomplete overlap and the generally low signal-to-noise ratio and signal artifacts above that layer. Our intercomparisons show that the water vapor correction leads to quite a good agreement between the extrapolated reference signal and the measurements in the 
case of CL51 ceilometers at one or more wavelengths in the specified range of the laser diode's emission. This ambiguity is due to the similar effective water vapor transmission at several wavelengths. In the case of CL31 and CS135 ceilometers the validation was not always successful. That suggests that error sources beyond the water vapor absorption might be dominant. For future applications we recommend monitoring the emitted wavelength and providing "dark" measurements on a regular basis.

\section{Introduction}

In the few last years a significant number of eye-safe singlewavelength backscatter lidars (ceilometers) have been installed for unattended operation. The primary reason to install ceilometer networks is the automation of synoptic observations, especially for the accurate determination of the cloud base height, but since approximately 2010 aerosol and ash remote sensing is considered an additional application. Though aerosols are relevant for radiative transfer, cloud physics and air quality, the main driver of this application was the need for surveillance of the airspace in the case of a volcanic eruption. The Eyjafjallajökull event in 2010 and the subsequent restrictions on civil aviation impressively demonstrated the benefit of ceilometers (e.g., Flentje et al., 2010; Wiegner et al., 2012). In parallel, efforts have been strengthened to derive not only mixing layer heights (e.g., Eresmaa et al., 2006; Münkel et al., 2007; Haeffelin et al., 2011; Lotteraner and Piringer, 2016; Kotthaus and Grimmond, 2018a) but also optical properties, primarily profiles of the particle backscatter coefficient $\beta_{\mathrm{p}}$ in a quantitative way. Recently ceilometer data were used for the validation of transport models, e.g., to improve forecasts of the dispersion of aerosol layers (e.g., Emeis et al., 2011; Cazorla et al., 2017; Chan et al., 2018) and to support air quality studies (e.g., Schäfer et al., 2011; Geiß et al., 2017; Kotthaus and Grimmond, 2018b), whereas data assimilation in numerical weather forecast models is still limited to case studies (e.g., Geisinger, 2017; Warren et al., 2018).

Ceilometer networks can be of particular benefit for the abovementioned purposes, when the spatiotemporal distribution of optical properties of particles is assessed in near real time. This requires a fully automated procedure, e.g., of quality control, calibration, overlap correction, cloud clearing and more. Accordingly a huge research and development effort was coordinated in the framework of the COSTAction TOPROF (Towards operational ground-based profiling with ceilometers, Doppler lidars and microwave radiometers for improving weather forecasts, Illingworth et al., 2018) to make ceilometers exploitable for aerosol and ash profiling. E-PROFILE was established as part of the European Meteorological Services Network (EUMETNET) Composite Observing System (EUCOS) to integrate the ceilometers in Europe into an operational network and to provide wellcalibrated and quality-controlled data in real time, hand-inhand with TOPROF. E-PROFILE's key activity is an operational data hub, which collects, processes and redistributes ceilometer data. The scientific code run on the hub has been developed in TOPROF.

The development of such a processing chain is complicated because national operators rely on automated (low power) lidars and ceilometers (often referred to as ALC) from different manufacturers. For example, the German Weather Service has installed CHM15k ceilometers (Lufft), whereas France, Finland and Switzerland rely on CL31 (Vaisala) for cloud detection. Sweden has set up a network of CL31 ceilometers and uses CBME-80 ceilometers (Eliasson) only on airports. In the UK both Lufft and Vaisala ceilometers are in operation. Compact micro-pulse lidars (MiniMPL) are used by Météo-France for volcanic ash detection, but a limited set of advanced lidar systems are also deployed, e.g., Polly ${ }^{X T}$ in Finland and Raymetrics systems in the UK. Recently, measurements of a CYY-2B ceilometer (CAMA) that was deployed in China were reported (Liu et al., 2018).

The primary goal of ceilometer measurements with respect to the quantitative retrieval of the aerosol optical properties is the provision of the particle backscatter coefficient $\beta_{\mathrm{p}}(z)$ (Wiegner and Geiß,2012). In this context the wavelength of the ceilometer is relevant: the abovementioned instruments operate either at $1064 \mathrm{~nm}$ (Lufft) or near $910 \mathrm{~nm}$ (Vaisala, Eliasson, Campbell, CAMA). The latter spectral range is influenced by water vapor absorption. As a consequence, it is only possible to determine aerosol optical properties with additional knowledge of the water vapor distribution and properties of the ceilometers' radiation source and with the application of a correction scheme. Only if $\beta_{\mathrm{p}}$ is derived with the best possible accuracy might it be used for estimates of further quantities (extinction coefficient, mass concentration), keeping in mind that the resulting accuracy is (drastically) reduced according to the accuracy of the inherent assumptions.

Even though water vapor absorption in the near infrared is well known, it was often ignored. Sundström et al. (2009) evaluated CL31 measurements from 2005 in Helsinki, when they assumed that absorption of water vapor could be neglected. The same assumption was made by Jin et al. (2015) using CL51 data. Comparisons of CL51 and CYY-2B measurements in Beijing, China, were also conducted without water vapor correction (Liu et al., 2018). Madonna et al. (2015) compared ceilometers by Lufft (CHM15k), Vaisala (CT25k) and Campbell (CS135s) in the framework of INTERACT (Potenza, Italy) but did not consider water vapor absorption quantitatively. To our knowledge, Markowicz et al. (2008) were the first to apply a correction term for water vapor absorption to data from a Vaisala CT25k ceilometer before deriving aerosol optical properties. Wiegner et al. (2014) discussed the problem in a general way on the basis of simulated signals and proposed an improved approach to 
correct for water vapor absorption. A follow-up paper (Wiegner and Gasteiger, 2015) developed a methodology that can routinely be applied to real measurements; it is used in the following. An alternative model was used by Madonna et al. (2018) and applied to CL51 and CS135 measurements during INTERACT II.

In summer 2015 a dedicated campaign, CeiLinEx2015 (ceilometer intercomparison experiment), was set up to better understand the performance of several commercially available ceilometers. In this paper we use data from this campaign to investigate whether signals can successfully be corrected for water vapor absorption. After a brief introduction to CeiLinEx2015 (next section), we discuss several approaches for the validation of the water vapor correction (Sect. 3). In the key part of our paper we discuss the main features of the validation procedure, especially the selection of the validation range and the spectral extrapolation, and select three representative atmospheric cases to scrutinize the validation. A short summary concludes the paper.

\section{CeiLinEx2015: description and objectives}

To support E-PROFILE and TOPROF, the Meteorological Observatory Hohenpeißenberg of the German Weather Service (DWD) has initiated an intercomparison campaign (CeiLinEx2015) at the Meteorological Observatory Lindenberg of the DWD in Lindenberg, Germany $\left(52.209^{\circ} \mathrm{N}\right.$, $14.122^{\circ} \mathrm{E}, 120 \mathrm{~m}$ a.m.s.l., above mean sea level). It took place from 1 June to 15 September 2015. Twelve ceilometers were deployed for continuous measurements: all instruments are commercially available systems as they are used in observational networks, by service providers, or research institutes. On the one hand, instruments from different manufacturers were set up, and different types from the same manufacturer were considered. On the other hand, two instruments of each type were installed to get a rough impression on the instrument-to-instrument variability. An overview of the deployed instruments is given in Table 1. The first column lists the acronyms of the instruments as they are used in our investigation. Note that the last column gives the vertical coverage of the data sets, which is larger than the range of data exploitable in a meteorological sense. The time resolution of raw data is in the range of $15-30 \mathrm{~s}$ and the vertical resolution is $10-15 \mathrm{~m}$.

CeiLinEx2015 was the first campaign since the WMO international ceilometer intercomparison (Jones et al., 1988) in 1986. Six different types of ceilometers from Vaisala, Lufft and Campbell Scientific were compared. According to the manufacturers, the emitted wavelength of the CL31 and CL51 is $910 \pm 10 \mathrm{~nm}$. To cope with the wavelength drift (with temperature) within the operating range of -40 to $60^{\circ} \mathrm{C}$, the optical filter of the receiving optics have quite a large bandwidth of $36 \mathrm{~nm}$ (at $50 \%$ transmissivity). As the Campbell ceilometers are temperature controlled, it is expected that the specified wavelength of $912 \mathrm{~nm}$ is quite stable; the spectral width of the laser diode is $\pm 3.5 \mathrm{~nm}$. Lufft's CHM15kx is a special version of the standard CHM15k ceilometer with tilted optical axes and a larger field of view that reduces the range of incomplete overlap. Note that the quite old LD40 ceilometers are not considered in this study.

The main goals of CeiLinEx2015 were twofold: the characterization of instruments and the retrieval of optical properties of aerosols $\left(\beta_{\mathrm{p}}\right)$. The former comprises the investigation of overlap properties, identification of measurement artifacts and studies on the instrument's sensitivity, e.g., to changes in the ambient temperature. The latter includes the calibration of the systems and the correction of the signals for water vapor absorption. Water vapor absorption is relevant for the Vaisala and Campbell ceilometers. Moreover, specific topics were covered, such as the comparison of derived cloud base heights and the derivation of the mixing layer height.

Four radiosondes per day are available in Lindenberg: at 00:00, 06:00, 12:00 and 18:00 UTC. Profiles of the air density, calculated from the measured temperature and pressure profiles, are used for the Rayleigh calibration. Measurements of the relative humidity are required for the water vapor correction. Ancillary data also include measurements from an AERONET (Holben et al., 1998) sun photometer, e.g., providing aerosol optical depths between 340 and $1640 \mathrm{~nm}$. This information can be used to extrapolate optical properties between different wavelengths.

Finally, the Polly XT lidar (Baars et al., 2016; Engelmann et al., 2016) RALPH was used as a reference system; CeiLinEx2015 was the first application of this instrument. It complies with the standard configuration of the EARLINET's research lidars (Pappalardo et al., 2014). Note that depolarization measurements were not relevant in the framework of this investigation. RALPH has been moved to Hohenpeißenberg, Germany, after the campaign to become part of EARLINET.

\section{Concepts of validation}

A strict validation of an aerosol profile derived from ceilometer measurements after applying a water vapor correction is not possible because no independent profile at the same wavelength is available. Thus, it is necessary to transform profiles between a water-vapor-contaminated wavelength and another wavelength for which high-quality data not subject to absorption are available. This extrapolation requires assumptions on the wavelength dependence of the optical properties of particles. Moreover, corrections for incomplete overlap or signal distortions might be required that are different for the ceilometers under review and the reference system. These are reasons for understanding the term "validation" as sort of an intercomparison and consistency check. Having this in mind we feel that it is nevertheless acceptable 
Table 1. List of deployed ceilometers in CeiLinEx2015: providers are DWD (German Weather Service), LMU (Ludwig Maximilian University of Munich), RUB (Ruhr-University Bochum), GCRI (Global Change Research Institute) and CSci (Campbell Scientific, manufacturer of the instruments). The emitted wavelength is given in nanometers, the vertical coverage in kilometers.

\begin{tabular}{llllrr}
\hline ID & Manufacturer & Type & Owner & Wavelength & Vertical coverage \\
\hline CHM-1 & Lufft & CHM15k & DWD & 1064 & 15.4 \\
CHM-2 & Lufft & CHM15k & DWD & 1064 & 15.4 \\
CHX-1 & Lufft & CHM15kx & LMU & 1064 & 15.4 \\
CHX-2 & Lufft & CHM15kx & DWD & 1064 & 15.4 \\
CL51-1 & Vaisala & CL51 & DWD & $\approx 910$ & 15.4 \\
CL51-2 & Vaisala & CL51 & GCRI & $\approx 910$ & 15.4 \\
CL31-1 & Vaisala & CL31 & DWD & $\approx 910$ & 7.7 \\
CL31-2 & Vaisala & CL31 & RUB & $\approx 910$ & 7.7 \\
CS-1 & Campbell & CS135 & CSci & $\approx 912$ & 7.7 \\
CS-2 & Campbell & CS135 & CSci & $\approx 912$ & 7.7 \\
LD-1 & Vaisala & LD40 & DWD & 855 & 15.3 \\
LD-2 & Vaisala & LD40 & DWD & 855 & 15.3 \\
\hline
\end{tabular}

to henceforward use the term "validation" to make the purpose and motivation of our investigation clearer.

There are several options for the validation of an aerosol profile. The most obvious strategies are either the comparison of signals $P(z)$, of attenuated backscatter $\beta^{*}(z)$ or of particle backscatter coefficients $\beta_{\mathrm{p}}(z), z$ being the height (vertically looking systems). These alternatives are discussed in the following.

\subsection{Concept based on signals}

To consider signals $P$ we determine the ratio of the signal $P\left(\lambda_{\text {off }}, z\right)$ at a wavelength that is not affected by water vapor absorption (e.g., $\lambda_{\text {off }}=1064 \mathrm{~nm}$ ) and $P\left(\lambda_{\text {on }}, z\right)$ that is affected (e.g., $\lambda_{\text {on }}=910 \mathrm{~nm}$ ). This results in a heightdependent conversion function $\eta(z)$ and allows us to extrapolate from one wavelength to the other. The conversion function $\eta(z)$ is defined as

$\eta(z)=\frac{P\left(\lambda_{\text {off }}, z\right)}{P\left(\lambda_{\text {on }}, z\right)}$,

assuming $\lambda_{\text {on }}<\lambda_{\text {off. }}$. The signal at the "water vapor wavelength" $\lambda_{\text {on }}$ is

$$
\begin{gathered}
P\left(\lambda_{\mathrm{on}}, z\right)=C_{\mathrm{L}} \frac{\beta\left(\lambda_{\mathrm{on}}, z\right)}{z^{2}} T_{\mathrm{m}}^{2}\left(\lambda_{\mathrm{on}}, z\right) T_{\mathrm{p}}^{2}\left(\lambda_{\mathrm{on}}, z\right) \\
T_{\mathrm{w}, \mathrm{eff}}^{2}\left(\lambda_{\mathrm{on}}, z\right) .
\end{gathered}
$$

Here, $T_{\mathrm{w}, \text { eff }}$ is the effective transmission due to water vapor absorption. As the emitted spectrum of the ceilometers is much broader than the width of individual absorption lines, an effective transmission representative for $\lambda_{\text {on }}$ is calculated following Wiegner and Gasteiger (2015). In this context the center wavelength of the emitted spectrum and - to a lesser extent - the full width at half maximum (assuming a Gaussian profile) $\Delta \lambda$ of the spectrum are crucial. $T_{\mathrm{m}}$ and $T_{\mathrm{p}}$ are the transmissions due to Rayleigh scattering and particle extinction, respectively, $C_{\mathrm{L}}$ is the lidar constant, and $\beta$ is the backscatter coefficient.

At the offline wavelength, the signal can be described according to

$P\left(\lambda_{\text {off }}, z\right)=C_{\mathrm{L}} \frac{\beta\left(\lambda_{\text {off }}, z\right)}{z^{2}} T_{\mathrm{m}}^{2}\left(\lambda_{\text {off }}, z\right) T_{\mathrm{p}}^{2}\left(\lambda_{\text {off }}, z\right)$.

For the transformation of the signal between $\lambda_{\text {on }}$ and $\lambda_{\text {off }}$ the lidar constant cancels out because we consider the same instrument. This leads to

$$
\begin{gathered}
\eta(z)=\frac{\beta\left(\lambda_{\text {off }}, z\right)}{\beta\left(\lambda_{\text {on }}, z\right)}\left(\frac{T_{\mathrm{m}}\left(\lambda_{\text {off }}, z\right)}{T_{\mathrm{m}}\left(\lambda_{\text {on }}, z\right)}\right)^{2}\left(\frac{T_{\mathrm{p}}\left(\lambda_{\text {off }}, z\right)}{T_{\mathrm{p}}\left(\lambda_{\text {on }}, z\right)}\right)^{2} \\
T_{\mathrm{w}, \mathrm{eff}}^{-2}\left(\lambda_{\text {on }}, z\right) .
\end{gathered}
$$

The backscatter term $B(z)$ - the first on the right-hand side of Eq. (4) - is

$$
\begin{aligned}
B(z) & =\frac{\beta\left(\lambda_{\text {off }}, z\right)}{\beta\left(\lambda_{\text {on }}, z\right)}=\frac{\beta_{\mathrm{m}}\left(\lambda_{\text {off }}, z\right)+\beta_{\mathrm{p}}\left(\lambda_{\text {off }}, z\right)}{\beta_{\mathrm{m}}\left(\lambda_{\text {on }}, z\right)+\beta_{\mathrm{p}}\left(\lambda_{\text {on }}, z\right)} \\
& =\frac{\beta_{\mathrm{m}}\left(\lambda_{\text {off }}, z\right)+\beta_{\mathrm{p}}\left(\lambda_{\text {off }}, z\right)}{L_{\mathrm{m}} \beta_{\mathrm{m}}\left(\lambda_{\text {off }}, z\right)+L_{\mathrm{p}}(z) \beta_{\mathrm{p}}\left(\lambda_{\text {off }}, z\right)} .
\end{aligned}
$$

The $\beta_{\mathrm{p}}$ profiles are obtained from a reference lidar operating at the absorption-free wavelength $\lambda_{\text {off. }}$. In Eq. (5) we have introduced the ratio $L_{\mathrm{p}}$ that is based on the Angström approach: we find

$$
L_{\mathrm{p}}(z)=\frac{\beta_{\mathrm{p}}\left(\lambda_{\text {on }}, z\right)}{\beta_{\mathrm{p}}\left(\lambda_{\text {off }}, z\right)}=\left(\frac{\lambda_{\text {on }}}{\lambda_{\text {off }}}\right)^{-\kappa(z)} \approx \frac{\tau_{\mathrm{p}}\left(\lambda_{\text {on }}\right)}{\tau_{\mathrm{p}}\left(\lambda_{\text {off }}\right)},
$$

with $\tau_{\mathrm{p}}$ as the aerosol optical depth and $\kappa$ the Angström exponent. Note that here we define $\kappa$ in terms of the backscatter coefficient derived from lidar measurements (e.g., 532 and $1064 \mathrm{~nm}$ ). The Angström exponent is mostly defined by 
means of the aerosol optical depth $\tau_{\mathrm{p}}$, e.g., retrieved from AERONET data. In the latter case it is implicitly considered constant with height, otherwise $\kappa$ can be determined as a height-dependent function. Analogously we get from the Rayleigh theory

$L_{\mathrm{m}}=\frac{\beta_{\mathrm{m}}\left(\lambda_{\text {on }}\right)}{\beta_{\mathrm{m}}\left(\lambda_{\text {off }}\right)}=\frac{\alpha_{\mathrm{m}}\left(\lambda_{\text {on }}\right)}{\alpha_{\mathrm{m}}\left(\lambda_{\text {off }}\right)}=\left(\frac{\lambda_{\text {on }}}{\lambda_{\text {off }}}\right)^{-4.08}>1$.

In case of an aerosol-free atmospheric layer (e.g., the free troposphere) and the abovementioned wavelengths (910 and $1064 \mathrm{~nm}) B(z)$ approaches $L_{\mathrm{m}}^{-1}=0.528$ in the case of a layer where $\beta_{\mathrm{p}} \gg \beta_{\mathrm{m}}$ is fulfilled $B(z) \approx L_{\mathrm{p}}^{-1}$, e.g., $B(z)=0.855$ if $\kappa=1$.

The second term on the right-hand side of Eq. (4) is calculated readily by

$$
\begin{aligned}
& \left(\frac{T_{\mathrm{m}}\left(\lambda_{\text {off }}, z\right)}{T_{\mathrm{m}}\left(\lambda_{\text {on }}, z\right)}\right)^{2}= \\
& \quad \exp \left\{-2 \int_{0}^{z} \alpha_{\mathrm{m}}\left(\lambda_{\text {off }}, z^{\prime}\right)\left(1-L_{\mathrm{m}}\right) \mathrm{d} z^{\prime}\right\}>1 .
\end{aligned}
$$

For the third term on the right-hand side of Eq. (4) we get

$$
\begin{aligned}
& \left(\frac{T_{\mathrm{p}}\left(\lambda_{\text {off }}, z\right)}{T_{\mathrm{p}}\left(\lambda_{\text {on }}, z\right)}\right)^{2}= \\
& \quad \exp \left\{-2 \int_{0}^{z} \alpha_{\mathrm{p}}\left(\lambda_{\text {off }}, z^{\prime}\right)\left(1-L_{\mathrm{p}}\left(z^{\prime}\right)\right) \mathrm{d} z^{\prime}\right\},
\end{aligned}
$$

which is typically larger than 1 . For Eq. (9) profiles of the particle extinction coefficient $\alpha_{\mathrm{p}}$ must be available from the reference lidar. Note that here we have used the common assumption that $\kappa$ based on backscatter coefficients (Eq. 6) or based on extinction coefficients (Eq. 9) is the same. This implies that, due to the fundamental relationship

$$
\frac{\beta_{\mathrm{p}}\left(\lambda_{\text {on }}\right)}{\beta_{\mathrm{p}}\left(\lambda_{\text {off }}\right)}=\frac{S_{\mathrm{p}}\left(\lambda_{\text {off }}\right)}{S_{\mathrm{p}}\left(\lambda_{\text {on }}\right)} \frac{\alpha_{\mathrm{p}}\left(\lambda_{\text {on }}\right)}{\alpha_{\mathrm{p}}\left(\lambda_{\text {off }}\right)},
$$

the lidar ratio $S_{\mathrm{p}}$ is the same at $\lambda_{\text {off }}$ and $\lambda_{\text {on }}$. The validity of this assumption can easily be checked by means of the online tool MOPSMAP (Gasteiger and Wiegner, 2018) if realistic assumptions of the aerosol type or the microphysical properties are available.

In the case of an atmosphere with height-independent Angström exponent $\kappa$, or if height independence must be assumed due to the lack of range-resolved data, Eqs. (8) and (9) can be simplified, and Eq. (4) can be written as

$$
\begin{gathered}
\eta(z)=\left(\frac{B(z)}{T_{\mathrm{w}, \mathrm{eff}}^{2}\left(\lambda_{\mathrm{on}}, z\right)}\right) T_{\mathrm{p}}^{2\left(1-L_{\mathrm{p}}\right)}\left(\lambda_{\mathrm{off}}, z\right) \\
T_{\mathrm{m}}^{2\left(1-L_{\mathrm{m}}\right)}\left(\lambda_{\text {off }}, z\right),
\end{gathered}
$$

with the transmissions $T_{\mathrm{p}}$ and $T_{\mathrm{m}}$ at wavelength $\lambda_{\text {off }}$. The vertical profile of $\eta$ is primarily governed by the vertical profile of $B(z)$. With Eq. (4) or Eq. (11) the measured signal at $\lambda_{\text {on }}$ can be transferred to $\lambda_{\text {off }}$ by Eq. (1) or vice versa for intercomparison, i.e., calibration of the systems is not required for this type of validation.

\subsection{Concept based on attenuated backscatter}

From the definition of the attenuated backscatter $\beta^{*}$,

$\beta^{*}(\lambda, z)=\frac{P z^{2}}{C_{\mathrm{L}}}$

and Eq. (1), it is directly clear that the ratio of the attenuated backscatter at the two wavelengths is

$\frac{\beta^{*}\left(\lambda_{\text {off }}, z\right)}{\beta^{*}\left(\lambda_{\text {on }}, z\right)}=\eta(z)$

Thus, the validation directly follows the mathematical formalism described in Sect. 3.1 because the underlying physical concept of both approaches is identical.

\subsection{Concept based on particle backscatter coefficients}

If the particle backscatter coefficient $\beta_{\mathrm{p}}$ is used for validation, the signals must be inverted. As shown by Wiegner and Gasteiger (2015) the measured Vaisala signals are first corrected for water vapor absorption by being multiplied with $T_{\mathrm{w} \text {.eff }}^{-2}\left(\lambda_{\mathrm{on}}\right)$. Subsequently a standard inversion technique (Klett, 1981; Fernald, 1984) is applied. This leads to $\beta_{\mathrm{p}}\left(\lambda_{\text {on }}\right)$ and the extrapolation to $\beta_{\mathrm{p}}$ at $\lambda_{\text {off }}$ can be performed by means of the Angström exponent with the same assumptions mentioned above. These profiles can be compared to inversions of measurements of RALPH. In contrast to the previous options, the inversion, however, requires the knowledge of the lidar ratio and calibrated signals. In the case of the ceilometers this might be an issue, as the signal-to-noise ratio in the free troposphere (under aerosol-free conditions) is low, and absolute calibration requires specific atmospheric conditions, i.e., long time series of measurements. As the same lidar ratio is used in both retrievals, a possible error of $S_{\mathrm{p}}$, however, would not influence the validation.

It is clear that this option is more complicated and includes more error sources. Though $\beta_{\mathrm{p}}(z)$ is a direct property of the particles in height $z$, whereas $P(z)$ and $\beta^{*}(z)$ do not only depend on aerosol properties in height $z$ but also on properties of the atmospheric path below $z$, we do not select this concept in our investigation.

\section{Validation: discussion and results}

Based on the previous discussion we focus on the validation of signals. In principle two alternative approaches are possible: either water-vapor-affected ceilometer signals near $910 \mathrm{~nm}\left(\lambda_{\text {on }}\right)$ are extrapolated to $1064 \mathrm{~nm}\left(\lambda_{\text {off }}\right)$ and compared to reference signals of RALPH, or one can extrapolate 
Table 2. The three validation cases.

\begin{tabular}{lll}
\hline Case & Date & Time \\
\hline A & 2 July 2015 & 00:00-03:00 UTC \\
B & 20 August 2015 & 05:00-08:00 UTC \\
C & 14 August 2015 & 00:00-03:00 UTC \\
\hline
\end{tabular}

RALPH signals to the water vapor domain and compare them with ceilometer measurements (Vaisala, Campbell). In this paper we decided to extrapolate the signal with the higher quality, i.e., we choose the second option.

The input required for the determination of the conversion function $\eta$ (Eq. 11) is available from CeiLinEx2015: to calculate $B(z)$ we use $\beta_{\mathrm{m}}$ from the Rayleigh theory with the air density derived from radiosondes. The transmission $T_{\mathrm{w}, \text { eff }}\left(\lambda_{\text {on }}\right)$ due to water vapor is calculated according to Wiegner and Gasteiger (2015) with the water vapor number density derived from the radiosondes as well, $L_{\mathrm{p}}$ is estimated using the Angström exponent $\kappa$ from AERONET or RALPH data, and $\beta_{\mathrm{p}}$ and $\alpha_{\mathrm{p}}$ are derived from the inversion of coincident RALPH measurements.

After defining our criteria for a successful validation in the following section we discuss the vertical range that is suitable for validation (Sect. 4.2) in detail, how the spectral extrapolation of aerosol optical properties is provided (Sect. 4.3) and the water vapor correction (Sect. 4.4). Three validation cases (see Table 2) that cover relevant atmospheric conditions are discussed in detail in Sect. 4.5: one case with the average water vapor amount $w$ (Case A), a second case with dry conditions (i.e., $T_{\mathrm{w}, \text { eff }}$ is large) and low $\tau_{\mathrm{p}}($ Case B) and a third case with large water vapor content (i.e., $T_{\mathrm{w}, \text { eff }}$ is small) and large $\tau_{\mathrm{p}}$ (Case C). Common to all cases is that the aerosol distribution was quite stable and no low clouds were present.

\subsection{Definition of criteria}

According to the previous section we use Eq. (1) to calculate a hypothetical RALPH signal at a wavelength in the water vapor regime; only integer numbers are considered.

$P\left(\lambda_{\text {on }}, z\right)=\frac{P\left(\lambda_{\text {off }}, z\right)}{\eta(z)}:=P_{\text {extra }}\left(\lambda_{\text {on }}, z\right)$

The term $P_{\text {extra }}\left(\lambda_{\text {on }}, z\right)$ is introduced to make clear that it is not a measurement but a signal extrapolated to $\lambda_{\text {on }}$. For a quantitative assessment of the agreement between $P_{\text {extra }}\left(\lambda_{\text {on }}, z\right)$ and the measured ceilometer signal $P_{\text {ceilo }}(z)$ at an actually unknown wavelength in the water vapor regime, we define the ratio $F$ as

$$
\begin{aligned}
& F\left(\lambda_{\text {on }}, z\right)=c_{\text {norm }} \frac{P_{\text {ceilo }}(z)}{P_{\text {extra }}\left(\lambda_{\text {on }}, z\right)} \\
& \text { with } c_{\text {norm }}=\left(\frac{1}{N} \sum_{i=1}^{N} \frac{P_{\text {ceilo }}\left(z_{i}\right)}{P_{\text {extra }}\left(\lambda_{\text {on }}, z_{i}\right)}\right)^{-1} .
\end{aligned}
$$

The normalization factor $c_{\text {norm }}$ is chosen as the average over the validation range, assuming $N$ range bins $z_{i}, i=$ $1, \ldots, N$. We call the range from $z_{1}$ to $z_{N}$ the "validation range". The choice of the lower range $z_{1}$ is influenced by the overlapping characteristics of the involved systems, the upper range by the signal-to-noise ratio and signal artifacts. These issues are discussed in detail in Sect. 4.2.

In the case of a correct treatment of the water vapor absorption, $F\left(\lambda_{\text {on }}, z\right)$ should not depend on the height $(\mathrm{d} F / \mathrm{d} z$ $=0)$; moreover, due to the normalization, $F\left(\lambda_{\text {on }}, z\right)$ should be 1 . If the decrease in the measured ceilometer signal with height is stronger (stronger attenuation) than that of the lidar extrapolated to the selected wavelength $\lambda_{\text {on }}$, i.e., $\mathrm{d} F / \mathrm{d} z$ is negative, then the assumed water vapor absorption at that wavelength is too small in comparison to the actual absorption. Positive $\mathrm{d} F / \mathrm{d} z$ corresponds to an overestimation of the absorption.

Consequently, we chose the minimum of the absolute value of the slope $\mathrm{d} F / \mathrm{d} z$ as the criterion for a correct treatment of the water vapor absorption. From this criterion theoretically the central wavelength of the emitted spectrum $\lambda_{\text {on }}$ can be derived and compared to the ceilometer's specification. In reality this is, however, not the case for several reasons: the exact emission spectrum of the laser is unknown, and absorption can be similar at different wavelengths. Note that $\lambda_{\text {on }}$ can be different for different ceilometers and time dependent. Having this in mind, several wavelengths should typically exist where the agreement between a ceilometer and extrapolated RALPH measurements is similar.

Additionally, the mean deviation of $F$ from unity in the validation range, $\Delta F$, given as a percentage and defined as

$$
\begin{aligned}
& \Delta F\left(\lambda_{\text {on }}, z\right)=\frac{100}{N} \sum_{1}^{N}\left(F^{\prime}\left(\lambda_{\text {on }}, z\right)-1\right), \\
& \text { with } F^{\prime}= \begin{cases}F & \text { for } F \geq 1 \\
F^{-1} & \text { for } F<1\end{cases}
\end{aligned}
$$

can be considered as a score. Finally, to strengthen the abovedescribed validation, an additional check has been applied; it is related to $F$ but maybe more descriptive. The decrease in the signal is estimated by fitting a straight line to the measured $P z^{2}$ (Vaisala or Campbell ceilometers) between $z_{1}$ and $z_{2}=z_{1}+\Delta z$ and is described by the ratio $s$ at these two ranges

$$
\begin{gathered}
\frac{P z_{1}^{2}}{P z_{2}^{2}}=s=\frac{\beta\left(\lambda_{\text {on }}, z_{1}\right)}{\beta\left(\lambda_{\text {on }}, z_{2}\right)} T_{\Delta, \mathrm{m}}^{-2}\left(\lambda_{\text {on }}\right) T_{\Delta, \mathrm{p}}^{-2}\left(\lambda_{\text {on }}\right) \\
T_{\Delta, \mathrm{w}, \mathrm{eff}}^{-2}\left(\lambda_{\text {on }}\right) .
\end{gathered}
$$

It can be compared with values expected from the lidar equation (right-hand side of Eq. 17) with $T_{\Delta}$ being the transmissions of the layer $\Delta z$ in the absorption spectral range caused by the different atmospheric constituents ( $m$, p and $\mathrm{w}$ for air molecules, particles and water vapor, respectively). 
Typically, we choose $\Delta z$ as the validation range as defined below. In this context it is assumed that within that layer the ratio $\beta_{\mathrm{p}}\left(z_{1}\right) / \beta_{\mathrm{p}}\left(z_{2}\right)$ is wavelength independent.

\subsection{The validation range}

To find a suitable validation range the investigation of the range of incomplete overlap of the lidar and the ceilometers is essential. It especially determines the lowest suitable range for the validation. Figure 1 shows the range-corrected reference signal (red solid line) and the corresponding signals (dashed) from the four Lufft ceilometers from Case A: CHX1 (blue), CHX-2 (green), CHM-1 (red) and CHM-2 (black). All measurements use the same wavelength, $\lambda=1064 \mathrm{~nm}$ and are thus directly comparable. They are scaled to match at $0.7 \mathrm{~km}$, and all ceilometer signals have been smoothed over \pm 3 range bins. In contrast to RALPH, the ceilometer data have undergone an overlap correction, determined by the manufacturer for each individual Lufft ceilometer. The corrections were introduced to make different ceilometers comparable, e.g., those deployed in the network of the German Weather Service. It should be recognized that with this information it is in principle possible to apply overlap correction functions determined from horizontal (e.g., Wiegner et al., 2014) or vertical measurements (e.g., Hervo et al., 2016) under homogeneous aerosol distributions.

It can be seen that the agreement of the signals of the CHM ceilometers (red and black lines) and RALPH is quite good above $0.5 \mathrm{~km}$, even above the mixing layer up to $4 \mathrm{~km}$. However, in the lowermost $500 \mathrm{~m}$ large discrepancies occur: the overlap correction for the CHX ceilometers (note that they are not part of the German Weather Service network) only show similar shapes, whereas the absolute values are quite different. Though the two CHM ceilometers agree well except in the lowermost range below $80 \mathrm{~m}$, they do not agree with the CHX-1 and CHX-2. This underlines the difficulty of determining accurate overlap corrections. Above the mixing layer height the CHX signals are quite noisy and especially the CHX-2 (green line) shows unrealistic profiles. Investigation of cases B and C (not shown) in general confirms these conclusions. Again, a surprisingly good agreement between the CHM and RALPH measurements in the lowermost 1$2 \mathrm{~km}$ of the free troposphere is found.

In Fig. 2 the corresponding intercomparison in the spectral regime of the water vapor absorption is shown. Vaisala ceilometers are shown as dashed lines, Campbell ceilometers as dashed-dotted lines. The reference signal of RALPH (red solid line) has been extrapolated to (as an example) $910 \mathrm{~nm}$, i.e., water vapor absorption is considered. All signals are scaled to match in $0.7 \mathrm{~km}$ and smoothed as above. It is immediately clear that the validation range is strongly limited. In this case it is certainly neither below $0.5 \mathrm{~km}$ nor above $1.3 \mathrm{~km}$. Inside this range it can be seen that the agreement between the CL51 signals (pink and black dashed lines) and the extrapolated reference signal seems to be almost perfect. In

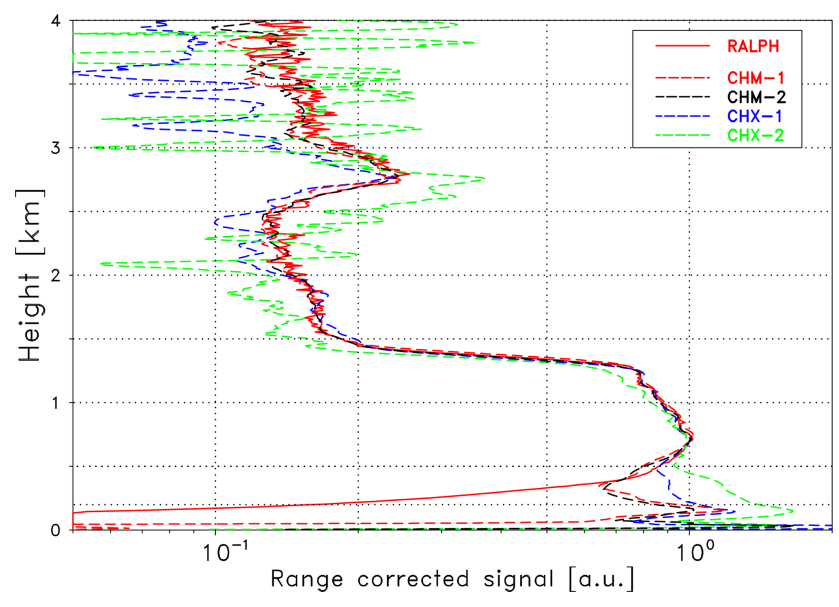

Figure 1. Range-corrected reference signal (RALPH) as a red solid line; the dashed lines refer to the Lufft ceilometers as indicated, all at $\lambda=1064 \mathrm{~nm}$ and scaled to match at $0.7 \mathrm{~km}$. Measurements concern Case A (see Table 2).

the lowermost part, where the signals suffer from incomplete overlap, no agreement is found. One reason for the missing overlap correction for RALPH has already been mentioned. The two CL51 profiles, however, do not match either, especially below $0.3 \mathrm{~km}$. This indicates that the generic overlap correction function provided by the manufacturer may not be applicable to all CL51 with the same accuracy. The agreement between the two CL31 profiles is quite good but does not agree with the CL51. No agreement is found between the two CS135 ceilometers, in particular the profile of the CS-1 (green dashed-dotted line) is totally different from the others. This example is in accordance of Fig. 1 and demonstrates that, due to the very large uncertainty of the overlap correction, a validation of the water vapor correction is impossible in the lowermost atmosphere, where aerosol backscattering is normally the largest.

Comparison of the signals above a height of approximately $1.4 \mathrm{~km}$ (Fig. 2) helps to assess the upper range of the validation range. The rapid decrease in the particle backscatter at the transition from the mixing layer to the free troposphere seems to raise problems in the data acquisition of all ceilometers and leads to quite a different drop in the signals. Another issue are signal artifacts characteristic for many ceilometers as described by Kotthaus et al. (2016) for the Vaisala CL31 ceilometer. Obviously, the increase in the range-corrected signal with height in the free troposphere is in contradiction to realistic signals from an (almost) aerosol-free atmosphere (Rayleigh atmosphere). A similar increase but smaller signals are found for the CS135 ceilometers, whereas the signals of the CL31 ceilometers (green and blue dashed lines) are totally attenuated.

From measurements with the termination hood - a device that blocks backscattered laser radiation - it is known that the range from 3 to $8 \mathrm{~km}$ is especially affected by artifacts. These 


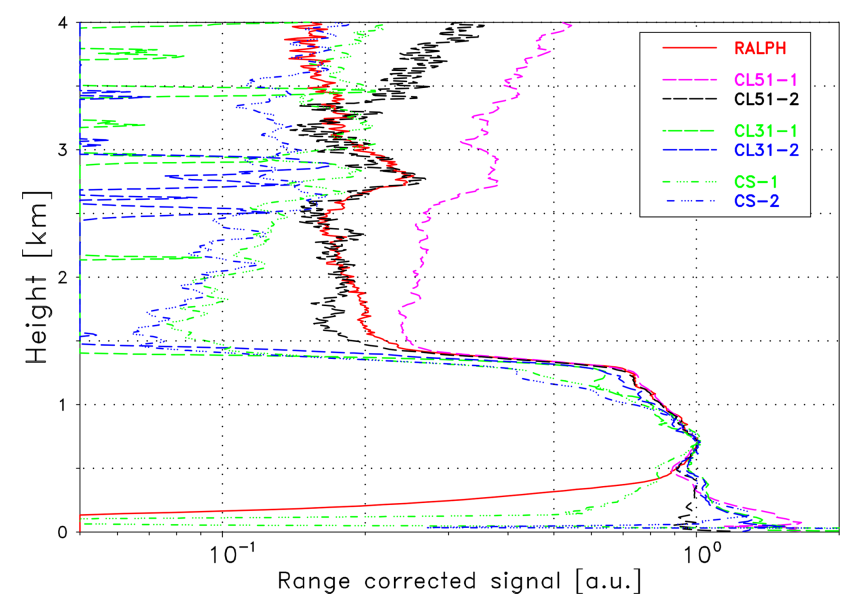

Figure 2. Range-corrected signals (Case A) of the reference lidar RALPH extrapolated by means of the conversion function $\eta$ to $910 \mathrm{~nm}$ (red solid line) and measurements of the ceilometers in the water vapor regime as indicated. All curves are in arbitrary units and scaled to match at $0.7 \mathrm{~km}$ altitude.

measurements are often referred to as dark measurements. In principle they can be used to correct ceilometer signals. The example of Case A shown in Fig. 3 should demonstrate its potential. The blue lines illustrate 10 different cases where different dark measurements have been subtracted from the CL51-1 signal. On the one hand, the slope of the signals in the free troposphere is much more realistic than before (pink dashed line in Fig. 2), on the other hand, most of the cases still do not show the slope as expected from Rayleigh scattering (see extrapolated RALPH measurement; red line) and the differences between the 10 profiles are considerable. Indeed dark measurements exhibit a certain temporal variability. Preliminary investigations within CeiLinEx2015 show that there is no significant correlation with temperature, and other reasons have not yet been identified. Accordingly, at the present state, this kind of correction does not provide the accuracy required to extend the validation range to altitudes above the mixing layer. Further investigations, including taking dark measurements on a regular basis, might improve the situation in future.

We conclude that the validation range is limited to the upper part of the mixing layer and has to be individually assessed for each specific measurement period. However, for a given time period, the same validation range is used for all ceilometers if not otherwise stated.

\subsection{The spectral extrapolation}

For the spectral extrapolation different options based on the Angström exponent are available. The most obvious approach is the use of AERONET data. This data set is well established and it is generally accepted that the accuracy is the best available. Several wavelengths are available so that the range of extrapolation is well covered. The disadvantage of

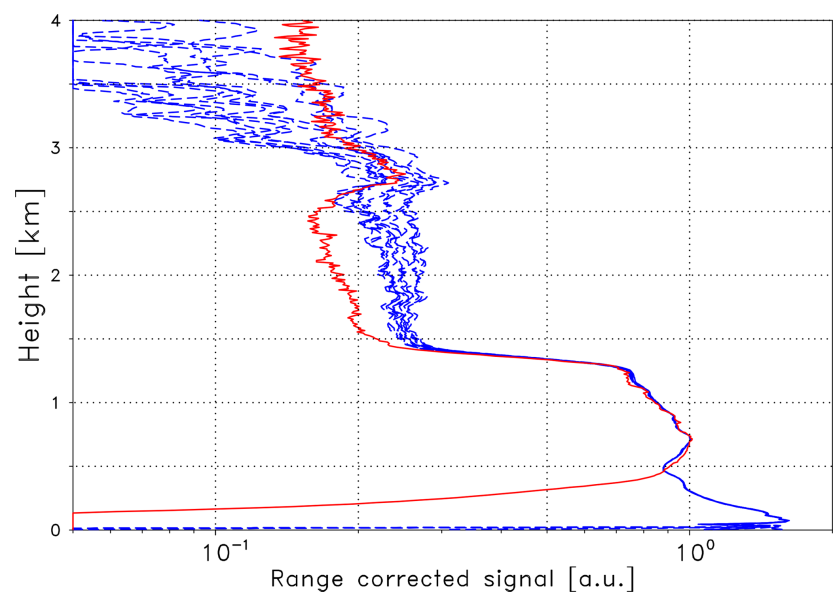

Figure 3. Range-corrected signals (Case A) of the reference lidar RALPH extrapolated by means of the conversion function $\eta$ to $910 \mathrm{~nm}$ (red line) and measurements of the CL51-1 ceilometer corrected by different dark measurements (blue lines). All curves are in arbitrary units and scaled to match at $0.7 \mathrm{~km}$ altitude.

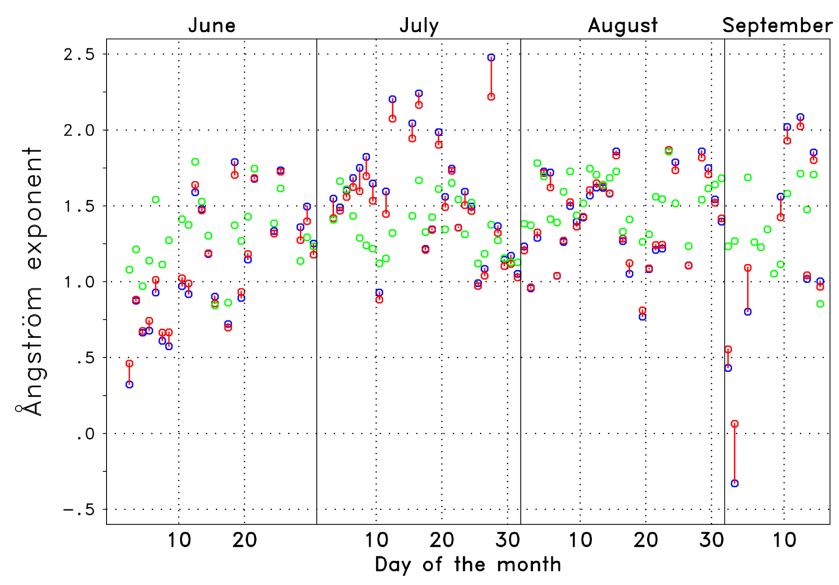

Figure 4. Angström exponent (daily averages) for the spectral range $1020-1640 \mathrm{~nm}$ (blue, $\kappa_{\mathrm{n}}$ ) and $870-1640 \mathrm{~nm}\left(\mathrm{red}, \kappa_{\mathrm{W}}\right)$, connected by a vertical line. For comparison the standard AERONET output for $440-870 \mathrm{~nm}$ (green, $\kappa_{\mathrm{a}}$ ) is shown.

AERONET measurements is the limitation to daytime conditions and the lack of range-resolved information as it relies on the aerosol optical depth. Range-resolved $\kappa(z)$ can only be derived from a reference lidar system using, however, a smaller set of wavelengths compared to a sun photometer. In case of RALPH either an Angström exponent based on backscatter coefficients $\beta_{\mathrm{p}}$ can be determined using measurements at 532 and $1064 \mathrm{~nm}$, or an Angström exponent based on extinction coefficients $\alpha_{\mathrm{p}}$ using the Raman channels at 355 and $532 \mathrm{~nm}$. In the latter case it is, however, questionable whether this spectral range is representative for the wavelength interval from $\lambda_{\text {on }}$ to $\lambda_{\text {off }}$ as $\kappa$ often is wavelength dependent (e.g., Kaskaoutis and Kambezidis, 2006; Schuster et al., 2006). 
AERONET data are available from 27 June to 15 September 2015. As cloud-free conditions are required, the temporal sampling is quite inhomogeneous. The measurements at Lindenberg comprises aerosol optical depth (level 2.0 data) at eight wavelengths between 340 and $1640 \mathrm{~nm}$. We calculate Angström exponents for three different spectral intervals: the standard AERONET output for $440-870 \mathrm{~nm}\left(\kappa_{\mathrm{a}}\right)$ and two intervals relevant for the interpolation from $\lambda_{\text {off }}$ to $\lambda_{\text {on }}$ : a narrow interval $1020-1640 \mathrm{~nm}\left(\kappa_{\mathrm{n}}\right)$ and wide interval $870-1640 \mathrm{~nm}\left(\kappa_{\mathrm{w}}\right)$. For the validation we may consider 1, 3 and $6 \mathrm{~h}$ averages as well as daily averages, depending on their availability. Note that a time lag of several hours between the AERONET data and the ceilometer data may occur if the validation period relies on ceilometer measurements during nighttime. An overview over the three Angström exponents $\left(\kappa_{\mathrm{a}}, \kappa_{\mathrm{n}}, \kappa_{\mathrm{w}}\right)$ based on daily averages is shown in Fig. 4. The two Angström exponents including $1640 \mathrm{~nm}$ (red and blue circles) are connected by a red vertical line to facilitate the discrimination from the standard Angström exponent.

The medians of daily averages of $\kappa$ are $\kappa_{\mathrm{a}}=1.38, \kappa_{\mathrm{n}}=$ 1.42 and $\kappa_{\mathrm{w}}=1.37$. For 1,3 and $6 \mathrm{~h}$ averages similar values are found. In total, all values are in the range expected for a continental site as Lindenberg. On the basis of individual observations, $\kappa_{\mathrm{a}}$ can be larger or smaller than the near-infrared values $\left(\kappa_{\mathrm{n}}, \kappa_{\mathrm{w}}\right)$, and differences larger than 0.5 can occur. This underlines that $\kappa$ can be wavelength dependent. Due to the high temporal variability shown in Fig. 4 it is recommended to use the Angström exponent closest to the actual ceilometer observations instead of long-term averages.

For the validation procedure, we choose $\kappa_{\mathrm{w}}$ in Eq. (6) as only this value completely covers the extrapolation range. To facilitate the reading we omit subscript $w$ from now on. To estimate the corresponding variability of $L_{\mathrm{p}}$ we again refer to Fig. 4: by applying the median of $\kappa=1.37$ we get $L_{\mathrm{p}}=1.239$, whereas for the 10 th percentile of $\kappa(=0.81)$ we get $L_{\mathrm{p}}=1.135$ and for the 90th percentile $(\kappa=1.83)$ we get $L_{\mathrm{p}}=1.331$. This uncertainty, together with the relative contribution of particles to the backscatter coefficient at a specific height, determines the uncertainty of $B(z)$.

The influence of $\kappa$ on the conversion function $\eta$ is illustrated in Fig. 5, Case A is selected as an example. Three representative wavelengths are displayed with the colors indicating $\lambda_{\text {on }}=905 \mathrm{~nm}$ (red), $910 \mathrm{~nm}$ (green) and $915 \mathrm{~nm}$ (blue). The full lines correspond to $\kappa=1.18$, the dashed to $\kappa=1.42$ - these values cover the expected range of Angström exponents for Case A (discussed in Sect. 4.5.1). The three lines being quite close to each other correspond to three different lidar ratios $(45,55,65 \mathrm{sr})$ with $S_{\mathrm{p}}=45 \mathrm{sr}$ marked by a circle. In general the profiles of $\eta$ are governed by the height dependence of $B(z)$ : below $0.5 \mathrm{~km}$ it is assumed that $\beta_{\mathrm{p}}(z)$ takes the value of $\beta_{\mathrm{p}}$ at $0.5 \mathrm{~km}$. This is a common procedure if an inversion of the lidar data is not possible due to the incomplete overlap. Until the upper part of the mixing layer $\eta$ is dominated by the increasing contribution of particles, whereas above the mixing layer $\eta(z)$ shows a pronounced

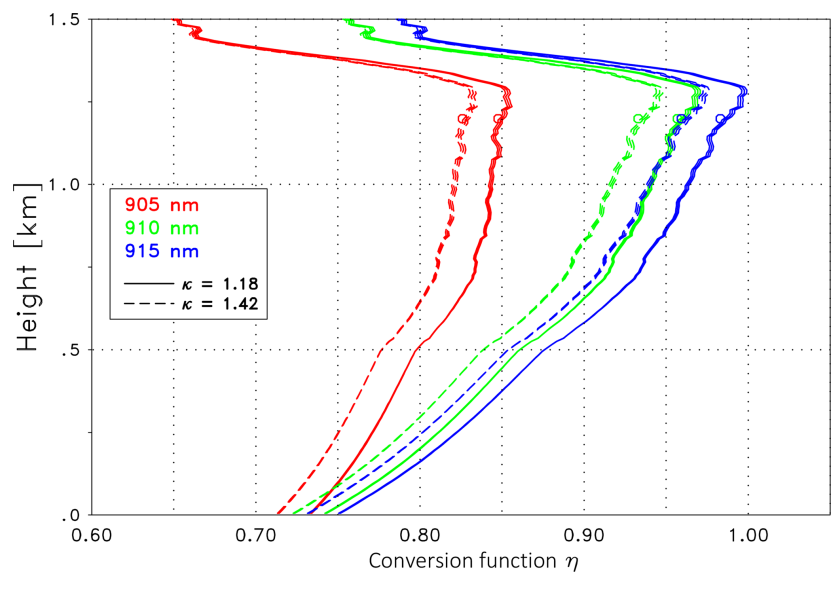

Figure 5. Conversion function $\eta$ at $905 \mathrm{~nm}$ (red), $910 \mathrm{~nm}$ (green) and $915 \mathrm{~nm}$ (blue) for Case A; $\kappa$ is assumed to be constant with height. The solid lines are for $\kappa=1.18$; the dashed lines are for $\kappa=1.42$. The three lines grouping together refer to different lidar ratios, with the smallest ( $S_{\mathrm{p}}=45 \mathrm{sr}$ ) marked with a circle.

decrease because $B(z)$ approaches its minimum value in the virtually aerosol-free layers as discussed previously in the context of Eq. (5). It can be seen that $\eta$ strongly depends on $\lambda$ and to a similar or smaller extent on $\kappa$, whereas the dependence on $S_{\mathrm{p}}$ is virtually negligible. As a consequence we use $S_{\mathrm{p}}=55 \mathrm{sr}$ for all validation of the ceilometer signals discussed below.

If the microphysical properties of particles significantly change with height, e.g., due to different aerosol types or due to strong hygroscopic growth, $\kappa$ will become height dependent, henceforward referred to as $\kappa(z))$. Then, for the assessment of $\kappa(z)$, the availability of $\beta_{\mathrm{p}}$ profiles (see Eq. 6) derived from measurements of a (at least) dual-wavelength reference lidar is mandatory. In the case of most aerosol lidars, the suitable wavelengths are 532 and $1064 \mathrm{~nm}$, an interval that unfortunately is quite wide compared to the difference between $\lambda_{\text {on }}$ and $\lambda_{\text {off }}$. To estimate the relevance of the height dependence we again consider Case A and assume two cases of an idealized height dependence: an increase from $90 \%$ to $110 \%$ of a given Angström exponent between the surface and the upper boundary of the mixing layer (here $1.3 \mathrm{~km}$ ) and the corresponding decrease. In Fig. 6 the conversion function $\eta$ for the same wavelengths as before are shown (indicated by the colors) and two mean Angström exponents with $\kappa=1.18$ and $\kappa=1.42$ as solid and dashed lines, respectively. The cases with an increasing or decreasing $\kappa$ are marked with crosses and circles, respectively. The remaining profile is based on the constant $\kappa$, already shown in Fig. 5. As mentioned above, $S_{\mathrm{p}}=55 \mathrm{sr}$ is assumed. Figure 6 reveals that a height dependence of $\kappa$ can have an influence on $\eta$ larger than the influence of $S_{\mathrm{p}}$. Though a generally valid magnitude cannot be assessed because of the variability on the atmospheric conditions (e.g., water vapor and aerosol 


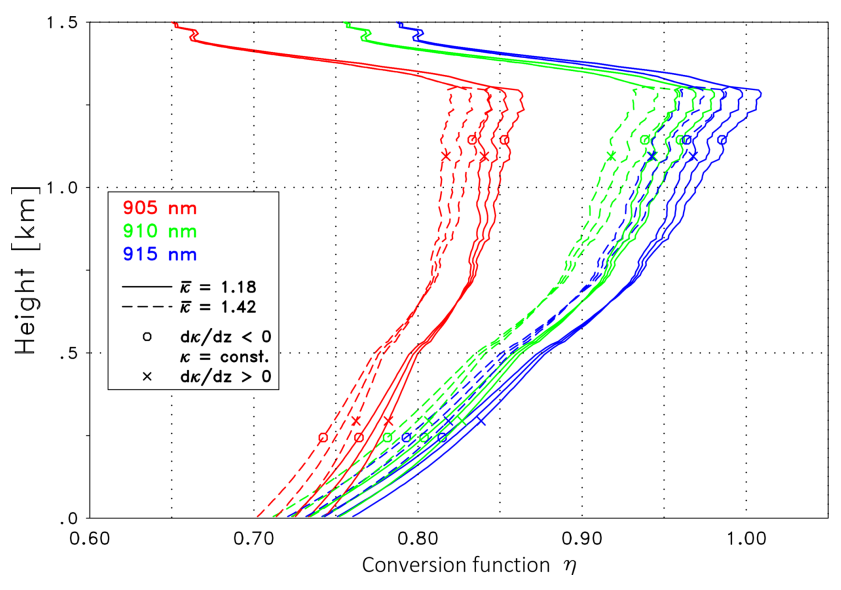

Figure 6. Conversion function $\eta$ at $905 \mathrm{~nm}$ (red), $910 \mathrm{~nm}$ (green) and $915 \mathrm{~nm}$ (blue) for Case A. Same as Fig. 5 but with idealized height-dependent $\kappa(z)$. The solid lines are for a mean Angström exponent of $\bar{\kappa}$ as indicated. The three lines grouping together refer to different $\kappa(z)$ profiles: $\kappa(z)$ decreasing and increasing with height is marked with a circle and cross, respectively, with the remaining curve showing the constant $\kappa$ (height independent); see text for details.

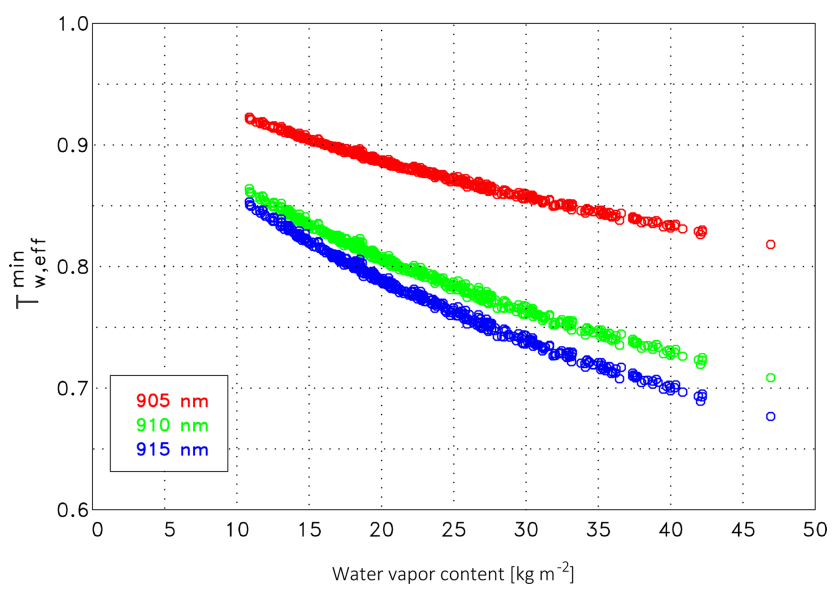

Figure 7. Relation between the total water vapor content $w$ and the water vapor transmission at $10 \mathrm{~km}, T_{\mathrm{w}, \mathrm{eff}}^{\mathrm{min}}$, determined from all radiosonde ascents between 27 June and 15 September 2015. The central wavelength of the laser spectrum is indicated in the legend.

distribution) and the spectrum of the laser source, this example demonstrates that the height dependence of $\kappa$ should be considered whenever reliable data are available. The difference of $\eta$ between height-dependent and height-independent Angström exponents itself is height dependent. A detailed discussion of different treatments of the spectral dependence is provided for each case in Sect. 4.5.

\subsection{The water vapor profiles}

The profile of the water vapor concentration is required to determine $T_{\mathrm{w}, \text { eff. }}$. It can be readily calculated as described

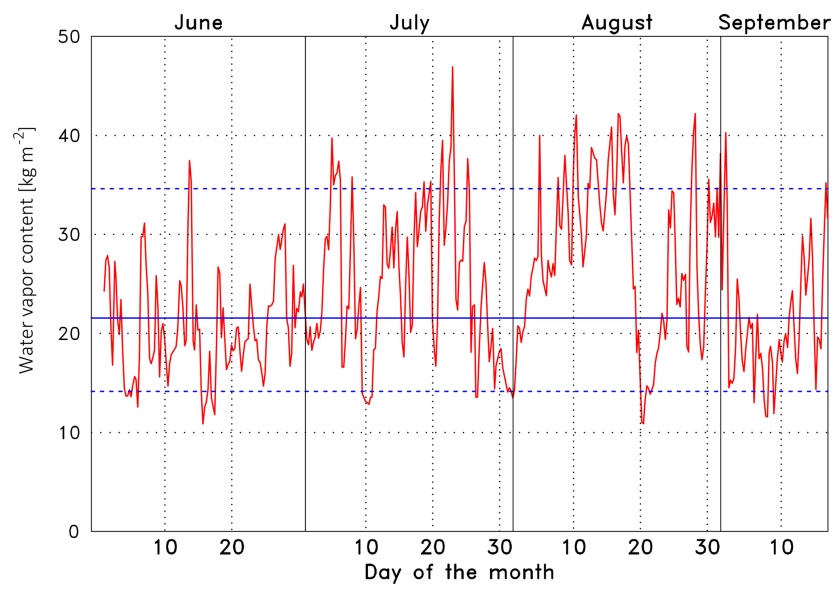

Figure 8. Total water vapor content (precipitable water) $w$ in $\mathrm{kg} \mathrm{m}^{-2}$ for each radiosonde ascent during the CeiLinEx2015 campaign. The horizontal lines indicate the median $\left(21.6 \mathrm{~kg} \mathrm{~m}^{-2}\right.$, solid) and the 10 th percentile $\left(14.1 \mathrm{~kg} \mathrm{~m}^{-2}\right)$ and 90th percentile (34.7 $\mathrm{kg} \mathrm{m}^{-2}$, dashed).

in Wiegner and Gasteiger (2015). A good indication of the overall influence of the water vapor correction on the validation is the total water content per unit area $w$ (in $\mathrm{kg} \mathrm{m}^{-2}$, precipitable water), as it determines the minimum transmission. Typically $T_{\mathrm{w} \text {,eff }}$ is virtually constant above 5 or $6 \mathrm{~km}$ due to the very low water vapor content above these heights. The relation between $w$ and $T_{\mathrm{w}, \mathrm{eff}}$ for $z=10 \mathrm{~km}$, henceforward referred to as $T_{\mathrm{w}, \text { eff }}^{\mathrm{min}}$, for three wavelength $\lambda_{\text {on }}$ $(905,910,915 \mathrm{~nm})$ is shown in Fig. 7. For example, $T_{\mathrm{w} . \mathrm{eff}}^{\min }$ at $910 \mathrm{~nm}$ (green dots) is approximately 0.856 and 0.730 for vapor contents of $w=12 \mathrm{~kg} \mathrm{~m}^{-2}$ and $w=40 \mathrm{~kg} \mathrm{~m}^{-2}$, respectively. Between $w=20 \mathrm{~kg} \mathrm{~m}^{-2}$ and $w=30 \mathrm{~kg} \mathrm{~m}^{-2}$, the transmission changes by $\mathrm{d} T_{\mathrm{w}, \mathrm{eff}}^{\min } / \mathrm{d} w \approx 0.0043 \mathrm{~m}^{2} \mathrm{~kg}^{-1}$. At $\lambda_{\text {on }}=905 \mathrm{~nm}$ (red dots), the water vapor absorption is weaker and the sensitivity is smaller $\left(0.0029 \mathrm{~m}^{2} \mathrm{~kg}^{-1}\right)$; at $915 \mathrm{~nm}$ (blue dots) the opposite is true $\left(0.0049 \mathrm{~m}^{2} \mathrm{~kg}^{-1}\right)$. The small scattering of the dots around a perfect line is caused by the fact that different water vapor profiles can result in the same $w$. The range of the actual total water vapor content between 27 June and 15 September, $w$, is shown in Fig. 8. This overview helps to select interesting conditions for the case studies discussed in Sect. 4.5. The median of the water vapor content is $w=21.6 \mathrm{~kg} \mathrm{~m}^{-2}$ (average $w=23.2 \mathrm{~kg} \mathrm{~m}^{-2}$ ), with the 10th percentile and the 90th percentile being $w=$ $14.1 \mathrm{~kg} \mathrm{~m}^{-2}$ and $w=34.7 \mathrm{~kg} \mathrm{~m}^{-2}$, respectively (blue lines). Together with Fig. 7 we can directly estimate the magnitude of the water vapor correction. If it is compared to the transmission of the air molecules $T_{\mathrm{m}}$ at $1064 \mathrm{~nm}$ (not shown) it is obvious that the water vapor effect is much more relevant. If we consider the profile of the median and the percentiles (10th, 90th) of $T_{\mathrm{m}}$ of all radiosonde ascents during CeiLinEx2015, we find that $T_{\mathrm{m}}>0.995$ throughout the troposphere and that the variability - expressed as the difference 


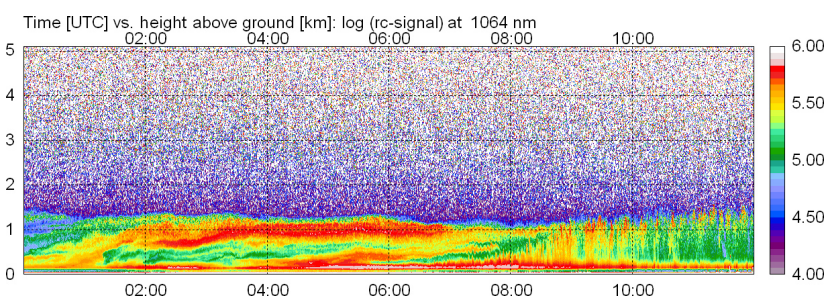

Figure 9. Time-height cross section of the range-corrected signal (in arbitrary units, logarithmic scale) of CHX-1 from 2 July 2015 (including Case A) to noon. Time is given in UTC, and the height above ground in kilometers; note that the vertical range shown here is not the full measurement range of the ceilometer.

between the two percentiles - is smaller than $1.4 \times 10^{-4}$, i.e., virtually negligible.

We conclude that in the framework of the validation we may use the same profile of the Rayleigh transmission, whereas individual measurements shall be used for the water vapor profile and the spectral dependence of the aerosol extinction.

\subsection{Results: The water vapor correction}

\subsubsection{Case A: 2 July 2015}

The first case study concerns a typical case with respect to the water vapor abundance. Measurements are taken from 2 July 2015. An overview of the aerosol distribution is shown in Fig. 9 as a time-height cross section of the range-corrected signal of the CHX-1 ceilometer (in arbitrary units, logarithmic scale). For the sake of clarity, only $12 \mathrm{~h}$ are shown and the maximum height is limited to $5.1 \mathrm{~km}$, though the maximum range of the ceilometer is $15.4 \mathrm{~km}$. It can be seen that until noon aerosol particles were mainly confined to the lowermost $1.5 \mathrm{~km}$. In the free troposphere aerosol-free conditions seem to occur. Until 07:00 UTC an elevated residual layer is visible, then convection drives the build-up of the mixing layer with a maximum depth of $1.7 \mathrm{~km}$. From a lidar perspective such a fair weather situation is considered to be quite stable. For the validation we select RALPH and ceilometer measurements averaged from 00:00 to 03:00 UTC to avoid daylight. Based on the criteria described in Sect. 4.2, the validation range is set to $0.7<z<1.3 \mathrm{~km}$.

The determination of the Angström exponent $\kappa$ was complicated as no level 2.0 data were available for 2 July; gaps of a few days in the AERONET record occur occasionally. If the closest daily average before (30 June, $\kappa=1.18$ ) and after the measurements ( 3 July, $\kappa=1.42$ ) are considered quite large, temporal differences have to be accepted, reducing the credibility of the values. For this reason we prefer to rely on level 1.0 data; here AERONET measurements from the morning of 2 July were available and a mean of 21 measurements was found with $\kappa=1.18 \pm 0.03$.
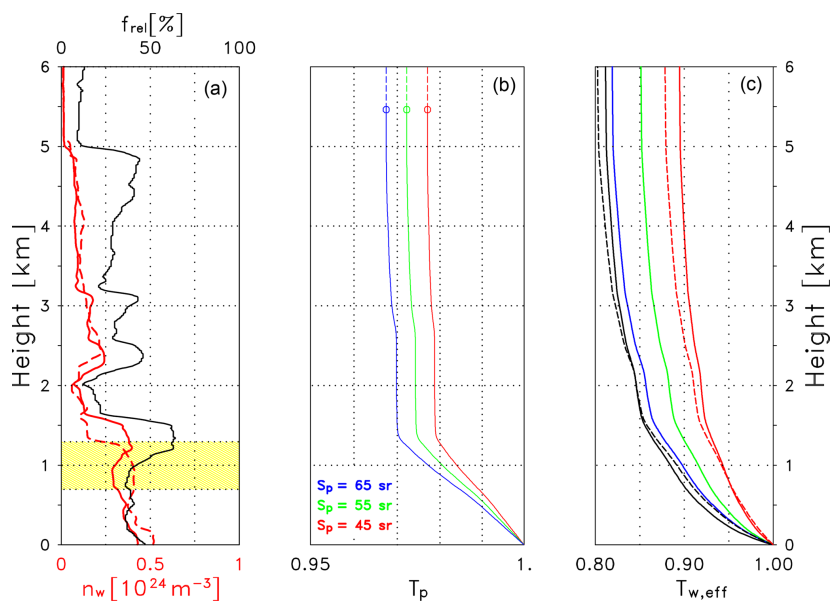

Figure 10. (a) Profile of the relative humidity (black line) in percent (see labels at the top) and profiles of the water vapor number density (in $10^{24}$ molecules $\mathrm{m}^{-3}$, labels at the bottom) for the 00:00 UTC ascent (solid red line) and the 06:00 UTC ascent (dashed red line). The validation range is indicated by the yellow area. (b) Particle transmission $T_{\mathrm{p}}$ at $1064 \mathrm{~nm}$ derived the from Klett inversion of RALPH signals (2 July 2015, 00:00-03:00 UTC, Case A) assuming a lidar ratio as indicated. The circles indicate the reference height. (c) Effective water vapor transmission $T_{\mathrm{w}, \text { eff }}$ for different laser wavelengths $\lambda_{\text {on }}$. Solid lines: $900 \mathrm{~nm}$ (black), $905 \mathrm{~nm}$ (red), $907 \mathrm{~nm}$ (green), $910 \mathrm{~nm}$ (blue). Dashed lines: $915 \mathrm{~nm}$ (black), $925 \mathrm{~nm}$ (red).

The scheduled 00:00 UTC radiosonde was launched at 22:50 UTC of the day before and provided the profiles required for the water vapor correction. Figure 10a shows the water vapor profile in terms of the relative humidity (black line, upper scale in percent) and the water vapor number density $n_{\mathrm{w}}$ (red lines, lower scale in $10^{24}$ molecules $\mathrm{m}^{-3}$ ). For comparison and as an indication of the temporal variability the number density from the subsequent radiosonde ascent ( $6 \mathrm{~h}$ later) is shown as dashed line. The water content was $18.3 \mathrm{~kg} \mathrm{~m}^{-2}$; thus it was slightly lower than the median. In the validation range (yellow area) the relative humidity increases with height from $35 \%$ to $65 \%$; i.e., it stays in a range where hygroscopic growth of hydrophilic aerosols (if present) is typically moderate.

The particle transmission $T_{\mathrm{p}}$ at $1064 \mathrm{~nm}$ is calculated from the RALPH measurements applying the backward Klett algorithm. We use a lidar ratio of $S_{\mathrm{p}}=55 \mathrm{sr}$ at $1064 \mathrm{~nm}$ and assume an uncertainty of $\pm 10 \mathrm{sr}$ for the $\alpha_{\mathrm{p}}$ retrieval. The reference height for the Rayleigh calibration is set to $5.47 \mathrm{~km}$. Because of the incomplete overlap of the lidar we assume that the particle extinction coefficient at $0.5 \mathrm{~km}$ does not change below. Above the reference height a constant $T_{\mathrm{p}}$ is assumed. The resulting profiles of $T_{\mathrm{p}}$ for three lidar ratios are shown in Fig. 10b: it can be seen that for $S_{\mathrm{p}}=55 \mathrm{sr}$ (green line) the transmission is $T_{\mathrm{p}}>0.97$ for all heights. A lidar ratio of $S_{\mathrm{p}}=45 \mathrm{sr}$ (red) and $S_{\mathrm{p}}=65 \mathrm{sr}$ (blue) led to quite a 


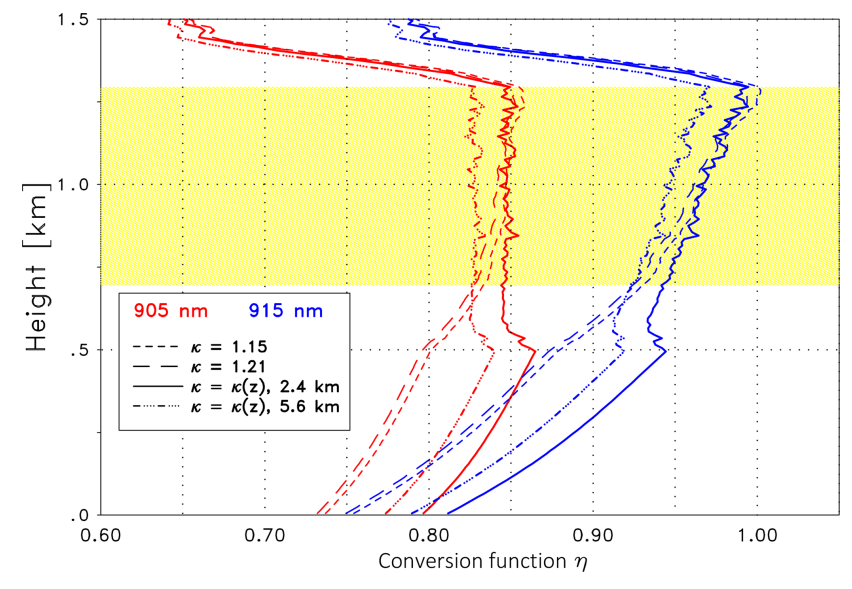

Figure 11. Conversion function $\eta$ at $905 \mathrm{~nm}$ (red) and $915 \mathrm{~nm}$ (blue) for Case A: the short- and long-dashed lines are for constant $\kappa$ with 1.15 and 1.21, respectively. The solid and dashed-dotted lines are calculated with a height-dependent $\kappa(z)$ when applying $\beta_{\mathrm{p}}$ profiles inverted from RALPH measurements with different reference values. $S_{\mathrm{p}}=55 \mathrm{sr}$ is assumed in all cases. The validation range between 0.7 and $1.3 \mathrm{~km}$ is highlighted in yellow (see text for details).

small change in $T_{\mathrm{p}}$, increasing with height but never exceeding $0.5 \%$. The same is true for $T_{\mathrm{p}}^{2\left(1-L_{\mathrm{p}}\right)}$ which appears in Eq. (11). The $\beta_{\mathrm{p}}(z)$ profile from the same Klett inversion is used to calculate $B(z)$. For reasons of consistency this implies that the backscatter coefficient $\beta_{\mathrm{p}}$ is assumed to be constant in the lowermost $0.5 \mathrm{~km}$.

The effective water vapor transmission $T_{\mathrm{w}, \text { eff }}$ is shown in Fig. 10c: the different lines refer to different wavelengths $\lambda_{\text {on }}$ between 900 and $925 \mathrm{~nm}$; the width of all spectra is set to $3.5 \mathrm{~nm}$. For example the transmission at $5 \mathrm{~km}$ decreases from 905 to $925,907,910,900$ and $915 \mathrm{~nm}$. The minimum transmission $T_{\mathrm{w} \text {,eff }}^{\mathrm{min}}$ for a broader range of wavelengths is summarized in Table 3. It can be seen that the minimum transmission varies between $0.8<T_{\mathrm{w}, \text { eff }}^{\min }<0.9$ depending on the wavelength: minimum absorption occurs between $904 \leq$ $\lambda_{\text {on }} \leq 905 \mathrm{~nm}$ and $920 \leq \lambda_{\text {on }} \leq 924 \mathrm{~nm}$, whereas absorption is strongest between $913 \leq \lambda_{\text {on }} \leq 916 \mathrm{~nm}$. As a consequence different wavelengths may result in virtually the same transmission. When compared to Fig. 7 it is obvious that - especially in the range around 907 and $918 \mathrm{~nm}$ - the transmission is much more sensitive to errors of the assumed wavelength $\lambda_{\text {on }}$ than to errors of the water vapor content. It can reach values of about $\mathrm{d} T_{\mathrm{w}, \text { eff }}^{\min } / \mathrm{d} \lambda>0.02 \mathrm{~nm}^{-1}$. In this context it is relevant that in the case of Vaisala ceilometers, the emitted spectrum is temperature dependent. A quantitative assessment of this dependence is, however, not yet available.

With this input the conversion function $\eta$ is determined. Examples of two representative wavelengths are displayed in Fig. 11, with the colors indicating $\lambda_{\text {on }}=905 \mathrm{~nm}$ (red) and $915 \mathrm{~nm}$ (blue). According to Fig. 10c the effective water vapor transmission is largest at $905 \mathrm{~nm}$, and thus $\eta$ takes the smallest values (Eq. 11). The dashed lines show the conversion function if a constant $\kappa$ is assumed: the short-dashed line corresponds to the smallest value of the assumed $\kappa$ range, the long-dashed to the largest value. The lidar ratio is set to $S_{\mathrm{p}}=$ $55 \mathrm{sr}$. Note that only the values within the validation range are relevant (yellow background); below that range, the incomplete overlap alters the values. The full lines are derived if a height-dependent Angström exponent derived from the particle backscatter coefficients at 532 and $1064 \mathrm{~nm}$ is used. The Angström exponent shows an almost linear increase from $\kappa$ $(z=0.7 \mathrm{~km})=1.04$ to $\kappa(z=1.3 \mathrm{~km})=1.21$ within the validation range (not shown). This suggests decreasing particle size; thus hygroscopic growth seems to not be dominant here. Note that the retrieved $\kappa(z)$ values match very well with the mean Angström exponent from the AERONET data ( $\kappa=1.18$; see above). Consequently the solid (red or blue) line lies between the corresponding dashed lines in Fig. 11 in the upper part of the validation range. The uncertainty of $\kappa(z)$ is slightly influenced by the sensitivity of $\beta_{\mathrm{p}}$ at $532 \mathrm{~nm}$ on the lidar ratio, i.e., $\pm 0.5 \%$ and $\pm 3 \%$ for the lower and upper boundaries of the validation range.

To extend the discussion we briefly consider the uncertainty that may be caused by the uncertainty of the Rayleigh reference height. The $1064 \mathrm{~nm}$ signal of RALPH suggests that heights around 2.4 and $5.6 \mathrm{~km}$ are suitable for the reference height; however, the signal at $532 \mathrm{~nm}$ has a small offset above $4 \mathrm{~km}$. Consequently, $\kappa(z)$ determined from $\beta_{\mathrm{p}}$ retrievals calibrated at the upper reference height can be used to investigate a worst case scenario; note that in most cases retrievals based on an incorrect Rayleigh calibration are, however, recognized and thus can be avoided. The resulting Angström exponent is considerably larger $(1.22<\kappa<1.44)$, but again a linear increase with height is found. The corresponding conversion functions $\eta$ are therefore shifted to smaller values but the vertical dependence is virtually unchanged, as shown from the dashed-dotted lines in Fig. 11.

The validation in terms of $\mathrm{d} F / \mathrm{d} z$ as a function of the wavelength is shown in Fig. 12. For an extensive discussion the two options introduced above are considered again: the assumption of a constant $\kappa$ from AERONET and a heightdependent $\kappa(z)$ from the RALPH-data inversion. The solid black line corresponds to the CL51-1, the red line to the CL51-2 measurements assuming a height-dependent $\kappa(z)$ and the default lidar ratio of $55 \mathrm{sr}$. The short-dashed and longdashed lines correspond to $S_{\mathrm{p}}=45 \mathrm{sr}$ and $S_{\mathrm{p}}=65 \mathrm{sr}$, respectively, to demonstrate the quite small uncertainty associated with the uncertainty of the lidar ratio. For comparison, $\mathrm{d} F / \mathrm{d} z$ assuming a constant $\kappa=1.18$, is shown as green (CL51-1) and blue (CL51-2) lines.

When considering $\kappa(z)$ we find the best agreement in the case of the CL51-1 measurements at $\lambda_{\text {on }}=918 \mathrm{~nm}$ with a slope $\mathrm{d} F / \mathrm{d} z=-3.9 \times 10^{-4} \mathrm{~km}^{-1}$ (marked by a circle in Fig. 12). The mean deviation $\Delta F=0.9 \%$ is quite small. At the wavelength $\lambda_{\text {on }}=918 \mathrm{~nm}$ water vapor absorption is comparably weak (cf. Table 3). Accordingly, and obvi- 
Table 3. Effective water vapor transmission at $10 \mathrm{~km}$ height, $T_{\mathrm{w}, \mathrm{eff}}^{\mathrm{min}}$, for different central wavelengths $\lambda_{\mathrm{on}}$ (in $\mathrm{nm}$ ) of the laser emission spectrum (water vapor profile of 2 July 2015).

\begin{tabular}{|c|c|c|c|c|c|c|c|c|c|c|c|c|}
\hline$\lambda_{\mathrm{on}}$ & 900 & 902 & 904 & 905 & 907 & 910 & 912 & 915 & 918 & 920 & 922 & 925 \\
\hline$T_{\mathrm{w}, \mathrm{eff}}^{\min }$ & 0.811 & 0.838 & 0.888 & 0.894 & 0.850 & 0.817 & 0.818 & 0.801 & 0.831 & 0.883 & 0.897 & 0.877 \\
\hline
\end{tabular}

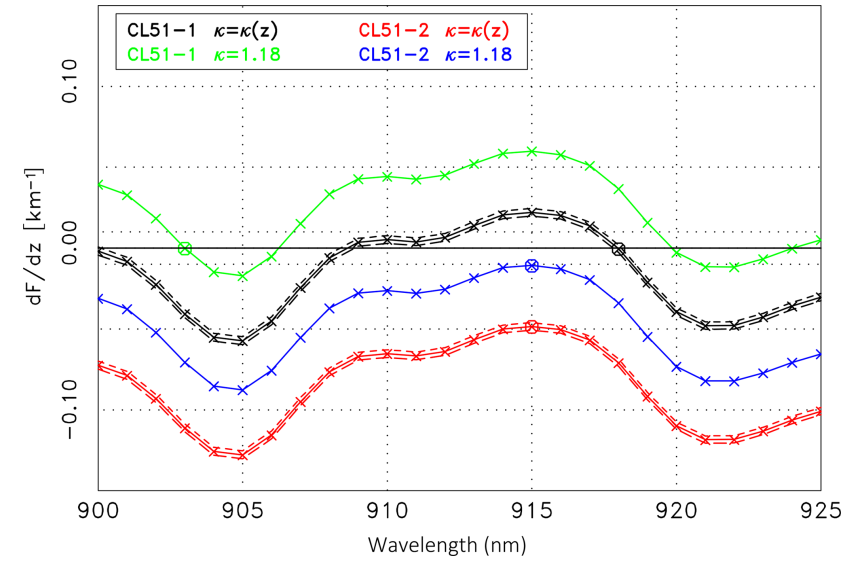

Figure 12. First derivative, $\mathrm{d} F\left(z, \lambda_{\text {on }}\right) / \mathrm{d} z$ (see Eq. 15), of the ratio of the CL51 ceilometer signal and the extrapolated reference lidar signal as a function of $\lambda_{\text {on }}$ : CL51-1 (solid black line) and CL51-2 (solid red line) assuming a height-dependent $\kappa(z)$. The short-dashed and long-dashed lines are for the minimum and maximum $S_{\mathrm{p}}$ values, respectively. The integer wavelength corresponding to the minimum of the absolute values of $\mathrm{d} F / \mathrm{d} z$ is indicated by a circle. The green (CL51-1) and blue (CL51-2) lines correspond to $\mathrm{d} F / \mathrm{d} z$ assuming a constant $\kappa$ derived from AERONET. All curves concern Case A.

ous from Fig. 12, similar absolute values of the slope (and $\Delta F$ ) are found when the reference signal is extrapolated to the wavelength of $900 \mathrm{~nm}$ or to a wavelength between $908 \leq \lambda_{\text {on }} \leq 912 \mathrm{~nm}$ - the quality of the agreement is virtually indistinguishable. The very small values of $\mathrm{d} F / \mathrm{d} z$ suggest a perfect water vapor correction, especially when noninteger values are considered as well. In the case of CL51-2 the best agreement is found for $\lambda_{\text {on }}=915 \mathrm{~nm}$, with $\mathrm{d} F / \mathrm{d} z=$ $-4.8 \times 10^{-2} \mathrm{~km}^{-1}$ (red circle in Fig. 12). Similar values are found in the range of $914-917 \mathrm{~nm}$, i.e., the strong part of the water vapor absorption band. The slope of the ratio is, however, almost 2 orders of magnitude larger than in the case of CL51-1 but still suggests a reasonable water vapor correction. The mean deviation $\Delta F=1.2 \%$ is somewhat larger compared to the CL51-1 evaluation.

In the case that the constant $\kappa$ from AERONET is used in the water vapor correction, the conclusions are similar for the CL51-1. Inspection of the green curve (Fig. 12) shows that again wavelengths can be found where the water vapor correction is perfect, e.g., 903, 906, 920 or $924 \mathrm{~nm}$. The best agreement is found for $903 \mathrm{~nm}$. The fact that this is a differ- ent wavelength than in the case of $\kappa(z)$ is irrelevant as long as the spectral emission of the laser is unknown. The minimum values of $\mathrm{d} F / \mathrm{d} z$ in the case of CL51-2 (blue curve) are also very small, underlining a very good water vapor correction. Somewhat surprising is that for Case A the constant $\kappa$ leads to better results than the height-dependent $\kappa$. This might be an effect of the long averaging time and the actual meteorological conditions.

We want to emphasize that this procedure does not allow us to retrieve the central wavelength of the laser spectrum. The reasons for this are not only the spectral ambiguity of the effective absorption, shown in Fig. 12, but also a certain degree of freedom in the choice of the validation range and how to weight the agreement at different altitudes. Nevertheless, the intercomparison demonstrates that a wavelength in the likely range of the laser emission can be found that leads to a very good agreement of the signals, in particular in the case of CL51-1. To emphasize this statement the ratio of the measured ceilometer signal (CL51-1 or CL51-2) and the original lidar signal at $1064 \mathrm{~nm}$ has been calculated: they show significantly larger slopes with $\mathrm{d} F / \mathrm{d} z=-0.06 \mathrm{~km}^{-1}$ and $-0.13 \mathrm{~km}^{-1}$, respectively. Such negative values are consistent with the fact that water vapor does not absorb at $1064 \mathrm{~nm}$. This example confirms that the water vapor correction indeed improves the aerosol retrieval.

To underline the correctness of signal slopes discussed above we have calculated the decrease in the signals $s$ (see Eq. 17), in the validation range with $z_{1}=0.7 \mathrm{~km}$ to $z_{2}=$ $1.3 \mathrm{~km}$. The ratio of the backscatter coefficients is $1.27 \pm$ 0.01. The contribution of the particles is calculated according to the Klett inversion of the RALPH signals. We assume the same aerosol type within the layer; thus the ratio $\beta_{\mathrm{p}}\left(z_{1}\right) / \beta_{\mathrm{p}}\left(z_{2}\right)$ is wavelength independent and can be used for $\lambda_{\text {on }} \approx 910 \mathrm{~nm}$ as well. The Rayleigh contribution to $\beta$ is calculated as usual from the air density derived from the radiosonde data. The transmission of the layer due to Rayleigh scattering $T_{\Delta, \mathrm{m}}$ is virtually 1 , and due to particle extinction $T_{\Delta, \mathrm{p}}=0.986 \pm 0.002$ depending on the lidar ratio as discussed above (Fig. 10b). This is equivalent to $T_{\Delta, \mathrm{p}}^{-2}=1.029 \pm$ 0.005 , used in Eq. (17). The effective water vapor transmission of the layer defined by the validation range is between $T_{\Delta, \mathrm{w}, \text { eff }}=0.977$ at $\lambda_{\text {on }}=905 \mathrm{~nm}$ as the lowest effective absorption, and $T_{\Delta, \mathrm{w}, \mathrm{eff}}=0.955$ at $\lambda_{\mathrm{on}}=915 \mathrm{~nm}$ (strongest absorption; see Fig. 10c). So the last term on the right-hand side of Eq. (17) should be between 1.047 and 1.096. From these estimates $s$ should be in the range $1.35<s<1.45$. Ac- 
Table 4. Relevant criteria of the validation for Case A. The minimum slope $\mathrm{d} F / \mathrm{d} z$ for an integer wavelength is given, or $\mathrm{d} F / \mathrm{d} z=0$ if the corresponding curve shown in Fig. 12 crosses the zero line (for an noninteger wavelength). According to Eq. (17) the decrease in the range-corrected signal $s$ should be $1.35<s<1.45$. A heightdependent $\kappa(z)$ is assumed.

\begin{tabular}{lrr}
\hline Ceilometer & $\mathrm{d} F / \mathrm{d} z$ & $s$ \\
\hline CL51-1 & 0 & 1.44 \\
CL51-2 & -0.048 & 1.50 \\
CL31-1 & -0.3 & 1.76 \\
CL31-2 & -0.19 & 1.63 \\
CS-1 & -0.89 & 2.56 \\
CS-2 & -1.1 & 2.95 \\
\hline
\end{tabular}

tually, we find $s=1.44$ and $s=1.50$ for CL51-1 and CL512 , respectively, which is reasonably close to this range and confirms the better water vapor correction for the CL51-1.

The same kind of validation is attempted for the other ceilometers. A brief overview with the values given above is summarized in Table 4.

For both CL31 ceilometers the decrease in the signals in the validation range was calculated according to Eq. (17), an illustration is already available in Fig. 2. For the CL311 (green dashed line) and CL31-2 (blue dashed), we find $s=1.76$ and $s=1.63$, respectively, and absolute values of the slope $\mathrm{d} F / \mathrm{d} z$ that are much larger than in the case of the CL51. Such a strong decrease cannot be explained by water vapor absorption at wavelengths around $910 \mathrm{~nm}$. As a consequence, we assume that the reason for the decrease in the signals is the low pulse energy of the CL31 compared to the CL51 ceilometers $(1.2 \mu \mathrm{J}$ vs. $3 \mu \mathrm{J})$. This hypothesis is supported by the fact that, immediately above the top of the mixing layer (approximately at $1.35 \mathrm{~km}$ ), the signals of both CL31 are totally attenuated. The profiles of both CS135 ceilometers are also shown in Fig. 2 (dashed-dotted lines). It is obvious that the slope of the range-corrected signal in the upper part of the mixing layer is much larger than in the case of all Vaisala ceilometers and the reference signal: in the validation range a decrease by a factor $s=2.56$ (CS-1, blue line) and $s=2.95$ (CS-2, green line) and very large negative slopes (see Table 4) are observed that are far beyond what can be caused by water vapor absorption according to Eq. (17). So again we conclude that the shape of the signals is dominated by currently unknown issues. The wavelength of the CS135 is, however, relatively stable due to the temperature control of the laser, so a wavelength drift is unlikely to be an issue. It might be possible that a further reduction of the validation range would help; however, a vertical extent of $0.6 \mathrm{~km}$ is already small.

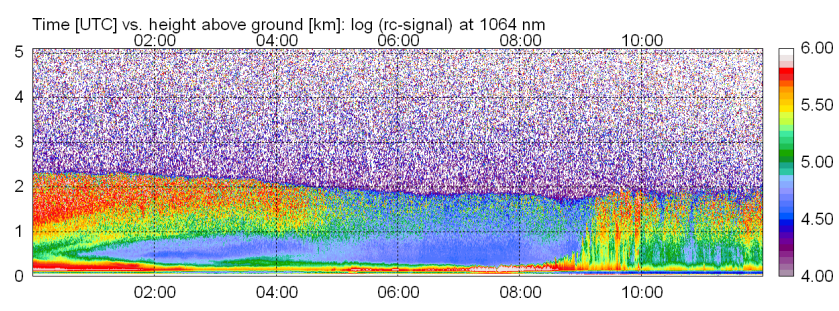

Figure 13. Time-height cross section of the range-corrected signal (in arbitrary units, logarithmic scale) of the CHX-1 from $20 \mathrm{Au}$ gust 2015 from midnight to noon (including Case B). Time is given in UTC and the height above ground in kilometers; note that the maximum height shown is not the full measurement range of the ceilometer.

\subsubsection{Case B: 20 August 2015}

As a second case study we selected the period from 05:00 to 08:00 UTC of 20 August 2015, referred to as Case B, with quite low total water vapor content (Fig. 8) of $w=$ $11.0 \mathrm{~kg} \mathrm{~m}^{-2}$ according to the 06:00 UTC radiosonde. The range-corrected signals of the CHX-1 ceilometer from midnight to noon are shown in Fig. 13 to illustrate the aerosol stratification of that day. The top of the aerosol layer was slowly decreasing from $2.3 \mathrm{~km}$ at midnight to $1.75 \mathrm{~km}$ at 09:00 UTC. Then convection led to a rapid increase in the mixing layer again. Compared to Case A its vertical extent of the aerosol layer was larger. The validation range was set to $0.75 \leq z \leq 1.55 \mathrm{~km}$.

The water vapor number density is shown in Fig. 14a: the black line indicates the profile of the relative humidity of the 06:00 UTC radiosonde (launched at 04:47 UTC), whereas the red lines show the number density $n_{\mathrm{w}}(06: 00$ and 12:00 UTC as solid and dashed lines, respectively). A very sharp decrease of $n_{\mathrm{w}}$ at $2.0 \mathrm{~km}$ can be found, which is in perfect agreement with the top of the aerosol layer (Fig. 13 at 05:00 UTC). The transmission of the particles $T_{\mathrm{p}}$ at $1064 \mathrm{~nm}$ (see Fig. 14b) is derived from RALPH measurements and similar to Case A (see Fig. 10b). This is plausible from AERONET measurements of the aerosol optical depth $\tau_{\mathrm{p}}$ : at $500 \mathrm{~nm} \tau_{\mathrm{p}}=0.11$ compared to $\tau_{\mathrm{p}}=0.10$ for Case A. The water vapor transmission $T_{\mathrm{w}, \text { eff }}$ for different wavelengths is larger than in Case $\mathrm{A}$, as the water vapor concentration was lower (see Fig. 14c).

The Angström exponent was derived from AERONET level 2.0 data between 04:56 and 11:38 UTC. From averaging 25 retrievals we found $\kappa_{\mathrm{w}}=1.10 \pm 0.14$, almost identical to $\kappa_{\mathrm{n}}$ but smaller than $\kappa_{\mathrm{a}}=1.30$. Thus, we assume a range of $0.96 \leq \kappa \leq 1.24$. The $\kappa(z)$ profile determined from the RALPH signals at 532 and $1064 \mathrm{~nm}$ shows an increase with height within the validation range from $\kappa=0.92$ to $\kappa=1.15$, which is in good agreement with the mean AERONET value.

With this input the conversion function $\eta$ is calculated according to Eq. (11). The results are shown in Fig. 15 - similar to Fig. 11 - for $905 \mathrm{~nm}$ (red) and $915 \mathrm{~nm}$ (blue). The dashed 

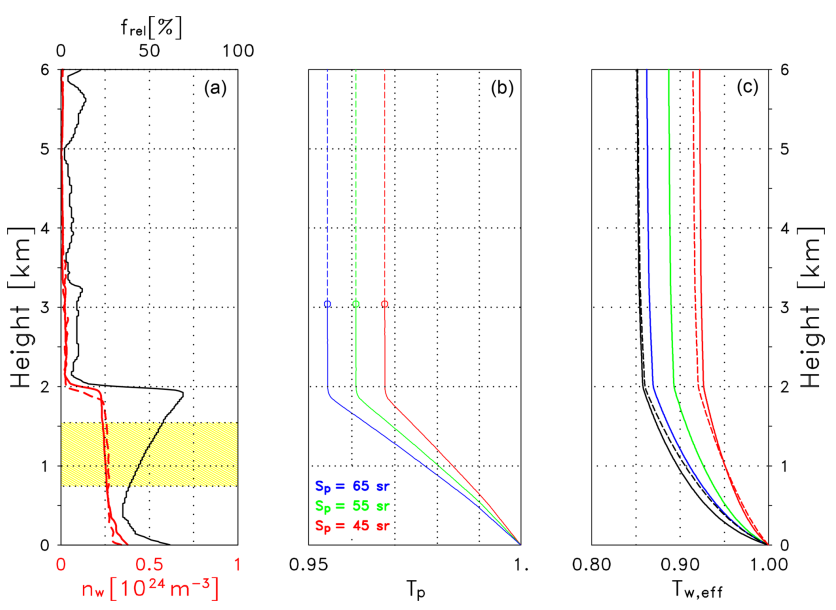

Figure 14. (a) Profile of the relative humidity (black line) in percent (see labels at the top) and profiles of the water vapor number density (in $10^{24}$ molecules $\mathrm{m}^{-3}$, labels at the bottom) for the 06:00 UTC radiosonde ascent (solid red line) and the 12:00 UTC ascent (dashed red line) of 20 August 2015. The validation range is highlighted in yellow. (b) Particle transmission $T_{\mathrm{p}}$ at $1064 \mathrm{~nm}$ derived from the Klett inversion of averaged RALPH signals (20 August 2015, 05:00-08:00 UTC, Case B) assuming a lidar ratio as indicated. The circles indicate the reference height. (c) Effective water vapor transmission $T_{\mathrm{w}, \text { eff }}$ for different laser wavelengths $\lambda_{\text {on }}$. Solid lines: $900 \mathrm{~nm}$ (black), $905 \mathrm{~nm}$ (red), $907 \mathrm{~nm}$ (green), $910 \mathrm{~nm}$ (blue); dashed lines: $915 \mathrm{~nm}$ (black), $925 \mathrm{~nm}$ (red)), analogously to Fig. 10.

lines concern the constant $\kappa$ assumption with $\kappa=0.96$ (short dashed) and $\kappa=1.24$ (long dashed) as the range of uncertainty of $\kappa$. The solid lines shows the conversion factor $\eta$ in the case of the height-dependent Angström exponent. The absolute values of the conversion functions $\eta$ are similar to Case A but the height dependence is quite different as expected from the radiosonde profiles (Figs. 10a and 14a). Again, the $S_{\mathrm{p}}$ dependence is negligible.

Having determined $\eta$, the validation is done analogously to Case A with the results summarized in Table 5. Figure 16 shows the wavelength dependence of $\mathrm{d} F / \mathrm{d} z$ for the CL511 (black solid line) and CL51-2 (red solid line), assuming a height-dependent $\kappa(z)$ and with the range due to the uncertainty of the lidar ratio indicated by the dashed lines of the same color. The best agreement is found for $\lambda_{\text {on }}=915 \mathrm{~nm}$ $\left(\mathrm{d} F / \mathrm{d} z=-2.2 \times 10^{-3} \mathrm{~km}^{-1}, \Delta F=0.7 \%\right)$ in the case of

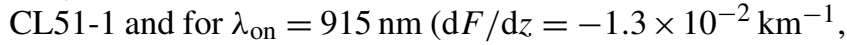
$\Delta F=0.8 \%)$ in the case of CL51-2. The dependence on $S_{\mathrm{p}}$ is negligible as was the case in Case A. The absolute values of $\mathrm{d} F / \mathrm{d} z$ are again much smaller than the corresponding values for $1064 \mathrm{~nm}\left(\mathrm{~d} F / \mathrm{d} z=-0.12\right.$ and $\left.-0.13 \mathrm{~km}^{-1}\right)$. The wavelength of the best agreement for CL51-2 is the same for Case A and Case B; however, this is solely a consequence of the criterion $(\|\mathrm{d} F / \mathrm{d} z\|=\min )$. According to Fig. 16 any wavelength in the range of strong absorption leads to a good agreement. For the CL51-1 we find a wavelength in the same range, whereas a wavelength in the moderate part of

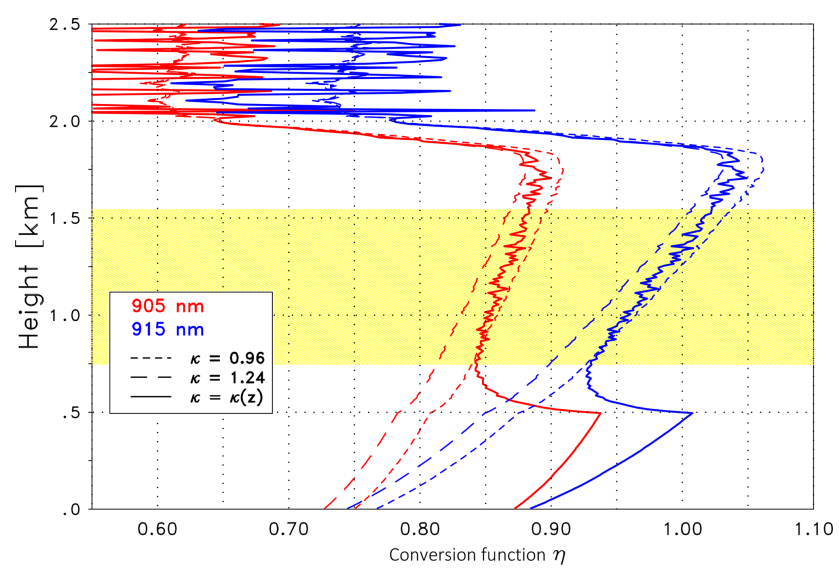

Figure 15. Analogously to Fig. 11, the conversion function $\eta$ is at $905 \mathrm{~nm}$ (red) and $915 \mathrm{~nm}$ (blue) for Case B. The dashed lines are for constant Angström exponents $\kappa$ as indicated, whereas the solid line is for the height-dependent $\kappa(z)$. The validation range (in yellow) was set to 0.75 and $1.55 \mathrm{~km}$.

Table 5. Relevant criteria of the validation for Case B. The minimum slope $\mathrm{d} F / \mathrm{d} z$ for an integer wavelength is given, or $\mathrm{d} F / \mathrm{d} z=0$ if the corresponding curve shown in Fig. 16 crosses the zero line (for an noninteger wavelength). According to Eq. (17) the decrease in the range-corrected signal $s$ should be $1.09<s<1.15$. A heightdependent $\kappa(z)$ is assumed.

\begin{tabular}{lrr}
\hline Ceilometer & $\mathrm{d} F / \mathrm{d} z$ & $s$ \\
\hline CL51-1 & -0.0022 & 1.10 \\
CL51-2 & -0.013 & 1.11 \\
CL31-1 & -0.28 & 1.37 \\
CL31-2 & -0.15 & 1.24 \\
CS-1 & 0 & 1.08 \\
CS-2 & -0.0089 & 1.04 \\
\hline
\end{tabular}

the absorption band $(918 \mathrm{~nm})$ was found in Case A. One can suspect that it is an effect of the different temperature of the CL51-1: it was between 31 and $28^{\circ} \mathrm{C}$ for Case A, whereas it was between 25 and $30^{\circ} \mathrm{C}$ for Case B. In contrast the temperature of the CL51-2 has changed less. However, the temperature dependence of the central wavelength of $0.27 \mathrm{~nm} \mathrm{~K}^{-1}$ (as specified by the manufacturer (see Wiegner and Gasteiger, 2015) is too small to explain this difference. A deeper discussion would be speculative as, due to the ambiguity of the effective absorption, a retrieval of $\lambda_{\text {on }}$ is not possible.

If a constant $\kappa$ is used for the calculation of $\eta$, the slopes $\mathrm{d} F / \mathrm{d} z$ are even smaller as obvious from the green (CL51-1) and blue (CL51-2) curves. In both cases we can find wavelengths yielding a perfect agreement with $\mathrm{d} F / \mathrm{d} z=0$.

The good agreement of the range-corrected signals ceilometer measurements vs. extrapolated reference measurements - is confirmed by their slope $s$ : from Eq. (17) we can expect that $1.09<s<1.15$ considering the uncertain- 


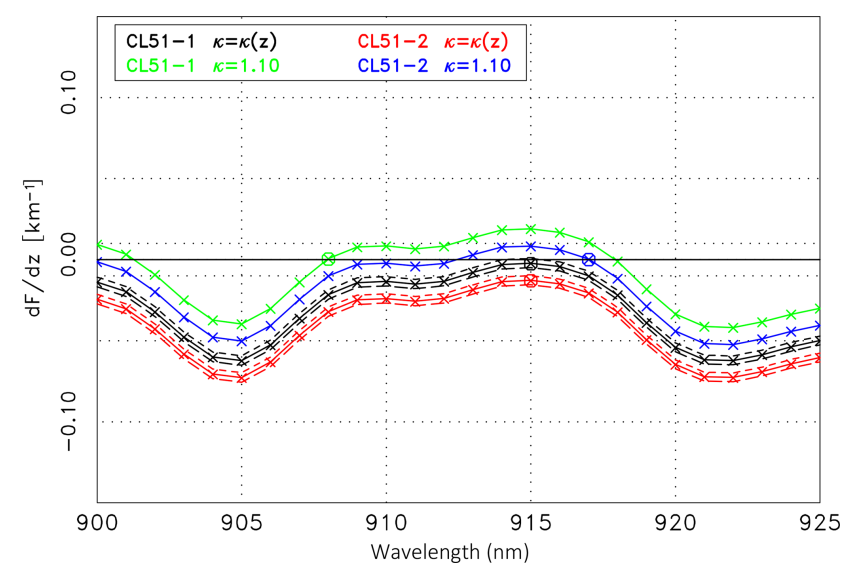

Figure 16. First derivative $\mathrm{d} F\left(z, \lambda_{\text {on }}\right) / \mathrm{d} z$ (see Eq. 15), of the ratio of the CL51 ceilometer signal and the extrapolated reference lidar signal as a function of $\lambda_{\text {on }}$ : analogously to Fig. 12, but for 20 August 2015, 05:00-08:00 UTC (Case B). The corresponding CL51 ceilometers and Angström exponent settings are indicated in the legend.

ties of the different contributions, whereas from the measurements of the CL51 ceilometers we get $s=1.10$ and $s=1.11$, respectively, i.e., an even better agreement than in Case A. For the CL31 ceilometers we again find larger $s$ values (1.37 and 1.24); they correspond to too strong a decrease in the signals to be explained by water absorption only. For Case B the slope of the range-corrected signals of both CS135 ceilometers is slightly smaller ( $s=1.08$ and $s=1.04$, respectively) but quite close to the expected range, and very small slopes $\mathrm{d} F / \mathrm{d} z$ are calculated. For the CS- 1 even a perfect agrement can be found at 908 and $918 \mathrm{~nm}$. For the specified emission wavelength of $912 \mathrm{~nm}$ we find $\mathrm{d} F / \mathrm{d} z=0.012$. If, however, the validation range is extended to $1.75 \mathrm{~km}$, the validation is not successful, suggesting deteriorated CS135 signals in the uppermost part of the mixing layer. This is not the case for the CL51 ceilometers.

\subsubsection{Case C: 14 August 2015}

The third case concerns 14 August 2015 with the time period from 00:00 to 03:00 UTC (see Table 2). The total water vapor content with $w=33.0 \mathrm{~kg} \mathrm{~m}^{-2}$ according to the 00:00 UTC radiosonde was quite large (see Fig. 8). The overview of the aerosol distribution from midnight to noon based on the range-corrected signal of the CHX-1 ceilometer is shown in Fig. 17. Elevated aerosol layers between approximately 0.8 and $3.0 \mathrm{~km}$, persisting for several hours after midnight, are the dominant feature. The optical depth at $500 \mathrm{~nm}$ - averaged over $6 \mathrm{~h}$ in the morning - was $\tau_{\mathrm{p}}=0.36$, which is well above the average. The validation range (yellow area in Fig. 18) was selected as $1.1<z<2.7 \mathrm{~km}$.

The Angström exponent was found to be $\kappa=1.55 \pm 0.014$ when averaging 18 AERONET retrievals between 04:47 and

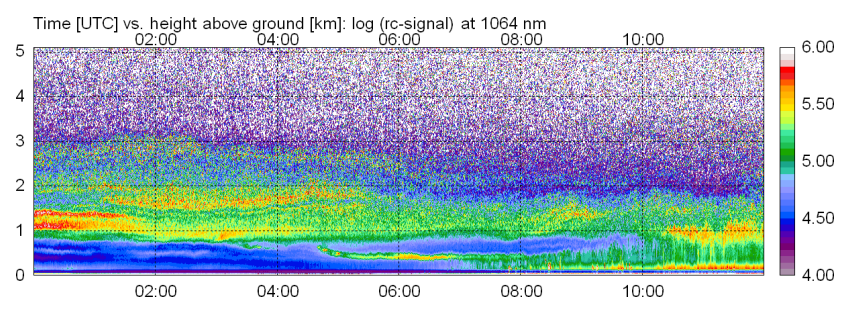

Figure 17. Time-height cross section of the range-corrected signal (in arbitrary units, logarithmic scale) of the CHX-1, similar to Fig. 9 but for 14 August 2015 (Case C).

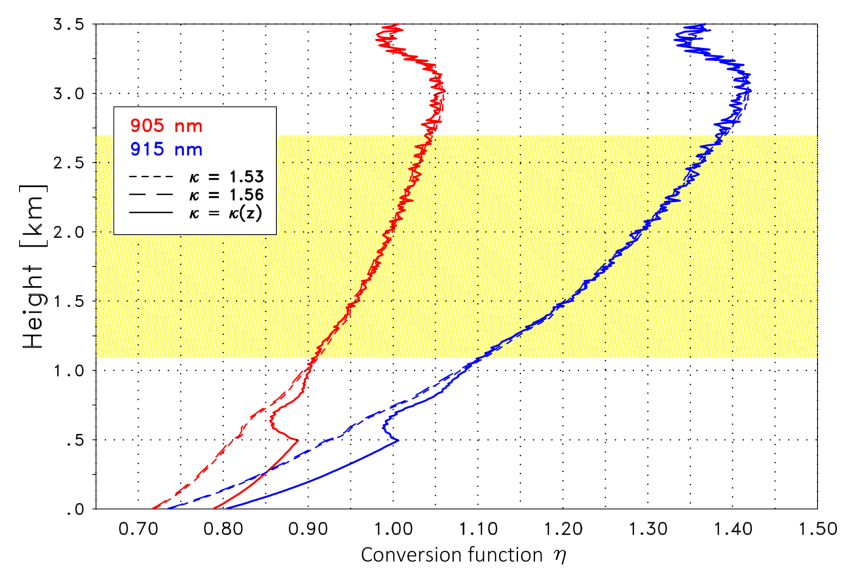

Figure 18. Analogously to Fig. 11, the conversion function $\eta$ is at $905 \mathrm{~nm}$ (red) and $915 \mathrm{~nm}$ (blue). The solid lines are for $\kappa(z)$ derived from the RALPH measurements; the dashed lines are for a constant $\kappa$ as indicated. The validation range is between 1.1 and $2.7 \mathrm{~km}$ (yellow area). Measurements are from 14 August 2015, 00:0003:00 UTC (Case C).

07:11 UTC. Compared to the previous cases $\kappa$ was quite large and the variability was very small. It perfectly agrees with the Angström exponent derived from $\beta_{\mathrm{p}}$ at 532 and $1064 \mathrm{~nm}$ : RALPH retrievals assuming $S_{\mathrm{p}}=55$ sr show an almost constant $\kappa(z)$ with $\kappa=1.57$ in an altitude of $1.1 \mathrm{~km}$ and $\kappa=1.62$ in $2.7 \mathrm{~km}$. Note that the uncertainty of $\kappa(z)$ due to the uncertainty of $S_{\mathrm{p}}$ is, however, comparably large in this case. With the typical assumption of $\pm 10 \mathrm{sr}$ for the uncertainty of $S_{\mathrm{p}}$ we get an uncertainty of $\kappa(z)$ of \pm 0.1 and \pm 0.05 at the lower and upper boundaries of the validation range.

The conversion function $\eta$ is calculated as before. The resulting profiles are shown in Fig. 18. Again, the red lines correspond to $905 \mathrm{~nm}$, whereas the blue lines are for $915 \mathrm{~nm}$. The solid lines are for the height-dependent $\kappa(z)$; the dashed lines for the constant $\kappa$ are derived from AERONET. According to the quite similar $\kappa$ value, differences of $\eta$ are almost negligible. Note that the $\eta$ values are significantly larger than in the previous cases with less atmospheric water vapor.

Results of the validation using extrapolated RALPH signals and CL51 ceilometer measurements are shown in Fig. 19. An overview of the relevant criteria is provided 
Table 6. Relevant criteria of the validation for Case C. The minimum slope $\mathrm{d} F / \mathrm{d} z$ for an integer wavelength is given, or $\mathrm{d} F / \mathrm{d} z=0$ if the corresponding curve shown in Fig. 12 crosses the zero line (for an noninteger wavelength). According to Eq. (17) the decrease in the range-corrected signal $s$ should be $1.46<s<1.72$.

\begin{tabular}{lrr}
\hline Ceilometer & $\mathrm{d} F / \mathrm{d} z$ & $s$ \\
\hline CL51-1 & 0 & 1.64 \\
CL51-2 & 0 & 1.67 \\
CL31-1 & -0.15 & 2.20 \\
CL31-2 & 0.019 & 1.50 \\
CS-1 & 0.15 & 1.18 \\
CS-2 & 0.22 & 1.06 \\
\hline
\end{tabular}

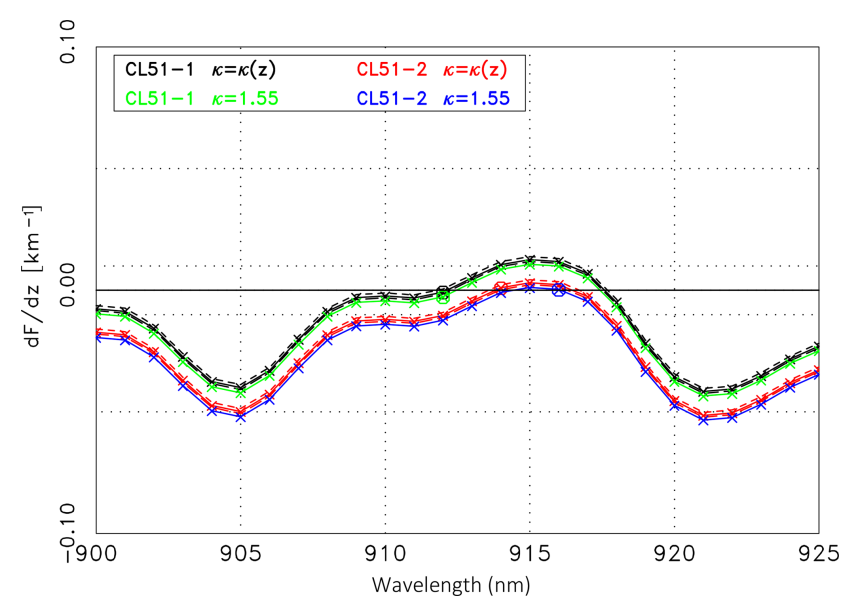

Figure 19. First derivative $\mathrm{d} F\left(z, \lambda_{\text {on }}\right) / \mathrm{d} z$ (see Eq. 15), of the ratio of the CL51 ceilometer signal and the extrapolated reference lidar signal as a function of $\lambda_{\text {on }}$, analogously to Fig. 12, but for $14 \mathrm{Au}-$ gust 2015, 00:00-03:00 UTC (Case C).

by Table 6 . Assuming the height-dependent $\kappa(z)$ slopes, $\mathrm{d} F / \mathrm{d} z=0$ can be found for both CL51 ceilometers. The values of $\|\mathrm{d} F / \mathrm{d} z\|$ are very small, and many integer wavelengths can be found that show slopes close to zero. Compared to the other examples, $\Delta F$ is slightly larger $(1.4 \%)$. If the AERONET-based $\kappa$ is used (green and blue line), perfect agreement is also found as expected from the similarity of the Angström exponents. The good agreement of the measured and extrapolated signals is confirmed by their slope $s$ : we find that $1.46<s<1.72$ considering the inherent uncertainties of the individual contributions to Eq. (17). The values derived from the measurements of the CL51 ceilometers are $s=1.64$ and $s=1.67$, respectively, and fall very well into the expected range. With respect to the other ceilometers only the water vapor validation in case of the CL31-2 is acceptable. The quite different results for the two CL31 ceilometers (see Table 6) shows that obvious differences occur even if the same type of ceilometer is evaluated. Note that, in spite of that, all ceilometers permit the determination of cloud base height and the detection of aerosol layers.

\section{Summary and conclusions}

The large number of ceilometers and the fact that they can be run unattended and fully automated makes them potentially very attractive for aerosol observations. Consequently, several attempts have been made to use them for aerosol remote sensing - though this does not comply with the intended use of the manufacturers. By exploiting ceilometer data in depth one becomes aware of the role of water vapor absorption and its influence on the retrieval of particle optical properties. Approaches that correct for this effect have been proposed recently (Wiegner and Gasteiger, 2015); however, a validation was still missing.

To assess the ceilometers' potential in a quantitative way, field campaigns were set up to compare them with reference lidar systems, to investigate their long-term stability and their operability in different environments. A corresponding activity was conducted in summer 2015 in Lindenberg, Germany, in the framework of the CeiLinEx2015 campaign. One of the scientific objectives was the abovementioned validation of retrieving aerosol optical properties in the case of water vapor absorption. The multi-wavelength Raman lidar RALPH served as a reference. The focus of this paper is on two types of Vaisala ceilometers (CL51 and CL31) and the CS135 of Campbell Scientific, all operating in the spectral range around $910 \mathrm{~nm}$, where water vapor absorption is significant.

Validation was performed on the basis of comparing backscatter signals. We extrapolate the reference signal from $1064 \mathrm{~nm}$ to the wavelengths of the ceilometers for validation and exploit the ratio of both. The validation was considered successful if a height-independent ratio could be found for any wavelength in the specified range of the emission; note that the actual wavelength is not exactly known. For this purpose the spectral dependence of particle optical properties has to be known; we use information either from coincident AERONET data or from the inversion of RALPH backscatter signals.

It turns out that the spectral extrapolation and the selection of the validation range are the most crucial points of the validation. In particular we recommend that the vertical range used for the validation should be selected very carefully; typically it is limited to the upper part of the mixing layer. The reason is that, on the one hand, the range of incomplete overlap cannot be corrected with sufficient accuracy; on the other hand, the ceilometer signals above the mixing layer are either too noisy or substantially influenced by signal artifacts. Consequently, different validation ranges might apply for each ceilometer.

It was demonstrated that the water vapor correction was successful in the case of the CL51 ceilometers. In the case of the CL31 and CS135 ceilometers the validation was not always successful: though the agreement between the measured signals and the extrapolated reference signal was better with than without correction, the agreement was in general, 
but not always, worse in comparison to the CL51. In particular for the CS135, no generally valid conclusions could be found. These findings, however, do not question the primary purpose of all ceilometers, the ability to determine cloud base height.

We conclude from the measurements during CeiLinEx2015 that, for the present state of the art of ceilometers, a correction for water vapor absorption that improves aerosol remote sensing seems to be reasonable for Vaisala CL51 ceilometers. For the other ceilometers participating in CeiLinEx2015, further studies are required as other error sources - not known in detail yet - seem to dominate the water vapor effect. Anyway, in all cases uncertainties remain as long as the emitted spectrum of the laser is unknown, but again, this does not affect, for example, mixing layer height retrievals or cloud height determination.

If in the future manufacturers of automated lidars and ceilometers aim at quantitative retrievals of aerosol optical properties, either the emitted wavelength should be monitored or wavelengths influenced by gaseous absorption should be avoided. In this context an investigation of the benefit of radiation at $808 \mathrm{~nm}$ for aerosol remote sensing applied by the Cimel CE372 lidar (Ancellet et al., 2019) would be interesting. Further steps are expected from an additional characterization of the hardware, monitoring metadata on relevant system parameters, and regular dark measurements to be able to correct for signal artifacts. All suggestions would not only help to improve future validation activities, but would also improve $\beta_{\mathrm{p}}(z)$ retrievals. We think that it is worthwhile to go in this direction as it offers a lot of new applications, e.g., the combination of passive and active remote sensing (e.g., Román et al., 2018).

Data availability. Data from the CeiLinEx2015 campaign are available from https://doi.org/10.5676/DWD/CEILINEX2015 (Pattantyús-Ábrahám et al., 2017).

Author contributions. MW conducted the study and prepared the paper with contributions from all authors. In particular JABA, AH and MHe provided substantial comments. IM, MPÁ, FW and YP processed the ceilometer data (setup of a uniform database, quality control and overlap correction). IM processed the reference lidar data. JG provided the water vapor absorption cross sections. MW, JC, KK and MB provided instruments. MB, CM and KP provided technical information on the ceilometers and the corresponding data sets. MHa promoted the idea of an intercomparison campaign within TOPROF including financial support. UG and RL were responsible for the setup and organization of the CeiLinEx2015 campaign.

Competing interests. The authors declare that they have no conflict of interest.
Acknowledgements. The CeiLinEx2015 measurement campaign received support for the organization and analysis of results from the European Cooperation in Science and Technology (COST; https://www.cost.eu/, last access: 22 January 2019) Action ES1303 "TOPROF". Juan Antonio Bravo-Aranda received funding from the Marie Sklodowska-Curie Action Cofund 2016 EU project - Athenea3i under grant agreement no. 754446. Josef Gasteiger has received funding from the European Research Council (ERC) under the European Union's Horizon 2020 research and innovation programme (grant no. 640458, A-LIFE).

We are grateful to Marc-Antoine Drouin (LMD, France) for developing pre-processing software for the CeiLinEx2015 data. Moreover, we want to thank Robert Begbie (DWD, Germany) and the staff at the Meteorological Observatory (DWD) in Lindenberg for the organization of CeiLinEx2015, technical support and maintenance of the ceilometers.

Edited by: Keding Lu

Reviewed by: Tianshu Zhang and Chengcai Li

\section{References}

Ancellet, G., Penner, I. E., Pelon, J., Mariage, V., Zabukovec, A., Raut, J. C., Kokhanenko, G., and Balin, Y. S.: Aerosol monitoring in Siberia using an $808 \mathrm{~nm}$ automatic compact lidar, Atmos. Meas. Tech., 12, 147-168, https://doi.org/10.5194/amt-12-1472019, 2019.

Baars, H., Kanitz, T., Engelmann, R., Althausen, D., Heese, B., Komppula, M., Preißler, J., Tesche, M., Ansmann, A., Wandinger, U., Lim, J.-H., Ahn, J. Y., Stachlewska, I. S., Amiridis, V., Marinou, E., Seifert, P., Hofer, J., Skupin, A., Schneider, F., Bohlmann, S., Foth, A., Bley, S., Pfüller, A., Giannakaki, E., Lihavainen, H., Viisanen, Y., Hooda, R. K., Pereira, S. N., Bortoli, D., Wagner, F., Mattis, I., Janicka, L., Markowicz, K. M., Achtert, P., Artaxo, P., Pauliquevis, T., Souza, R. A. F., Sharma, V. P., van Zyl, P. G., Beukes, J. P., Sun, J., Rohwer, E. G., Deng, R., Mamouri, R.-E., and Zamorano, F.: An overview of the first decade of Polly ${ }^{N E T}$ : an emerging network of automated Raman-polarization lidars for continuous aerosol profiling, Atmos. Chem. Phys., 16, 5111-5137, https://doi.org/10.5194/acp16-5111-2016, 2016.

Cazorla, A., Casquero-Vera, J. A., Román, R., Guerrero-Rascado, J. L., Toledano, C., Cachorro, V. E., Orza, J. A. G., Cancillo, M. L., Serrano, A., Titos, G., Pandolfi, M., Alastuey, A., Hanrieder, N., and Alados-Arboledas, L.: Near-real-time processing of a ceilometer network assisted with sun-photometer data: monitoring a dust outbreak over the Iberian Peninsula, Atmos. Chem. Phys., 17, 11861-11876, https://doi.org/10.5194/acp-17-118612017, 2017.

Chan, K. L., Wiegner, M., Flentje, H., Mattis, I., Wagner, F., Gasteiger, J., and Geiß, A.: Evaluation of ECMWF-IFS (version 41R1) operational model forecasts of aerosol transport by using ceilometer network measurements, Geosci. Model Dev., 11, 3807-3831, https://doi.org/10.5194/gmd-11-3807-2018, 2018.

Emeis, S., Forkel, R., Junkermann, W., Schäfer, K., Flentje, H., Gilge, S., Fricke, W., Wiegner, M., Freudenthaler, V., Groß, S., Ries, L., Meinhardt, F., Birmili, W., Münkel, C., Obleitner, F., and Suppan, P.: Measurement and simulation of the $16 / 17$ 
April 2010 Eyjafjallajökull volcanic ash layer dispersion in the northern Alpine region, Atmos. Chem. Phys., 11, 2689-2701, https://doi.org/10.5194/acp-11-2689-2011, 2011.

Engelmann, R., Kanitz, T., Baars, H., Heese, B., Althausen, D., Skupin, A., Wandinger, U., Komppula, M., Stachlewska, I. S., Amiridis, V., Marinou, E., Mattis, I., Linné, H., and Ansmann, A.: The automated multiwavelength Raman polarization and water-vapor lidar Polly ${ }^{\mathrm{X}}$ : the neXT generation, Atmos. Meas. Tech., 9, 1767-1784, https://doi.org/10.5194/amt-9-1767-2016, 2016.

Eresmaa, N., Karppinen, A., Joffre, S. M., Räsänen, J., and Talvitie, H.: Mixing height determination by ceilometer, Atmos. Chem. Phys., 6, 1485-1493, https://doi.org/10.5194/acp-6-1485-2006, 2006.

Fernald, F. G.: Analysis of atmospheric lidar observations: some comments, Appl. Optics, 23, 652-653, 1984.

Flentje, H., Claude, H., Elste, T., Gilge, S., Köhler, U., PlassDülmer, C., Steinbrecht, W., Thomas, W., Werner, A., and Fricke, W.: The Eyjafjallajökull eruption in April 2010 - detection of volcanic plume using in-situ measurements, ozone sondes and lidar-ceilometer profiles, Atmos. Chem. Phys., 10, 10085-10092, https://doi.org/10.5194/acp-10-10085-2010, 2010.

Gasteiger, J. and Wiegner, M.: MOPSMAP v1.0: a versatile tool for the modeling of aerosol optical properties, Geosci. Model Dev., 11, 2739-2762, https://doi.org/10.5194/gmd-112739-2018, 2018.

Geisinger, A., Behrendt, A., Wulfmeyer, V., Strohbach, J., Förstner, J., and Potthast, R.: Development and application of a backscatter lidar forward operator for quantitative validation of aerosol dispersion models and future data assimilation, Atmos. Meas. Tech., 10, 4705-4726, https://doi.org/10.5194/amt10-4705-2017, 2017.

Geiß, A., Wiegner, M., Bonn, B., Schäfer, K., Forkel, R., von Schneidemesser, E., Münkel, C., Chan, K. L., and Nothard, R.: Mixing layer height as an indicator for urban air quality?, Atmos. Meas. Tech., 10, 2969-2988, https://doi.org/10.5194/amt10-2969-2017, 2017.

Haeffelin, M., Angelini, F., Morille, Y., Martucci, G., Frey, S., Gobbi, G. P., Lolli, S., O’Dowd, C. D., Sauvage, L., XuerefRémy, I., Wastine, B., and Feis, D. G.: Evaluation of MixingHeight Retrievals from Automatic Profiling Lidars and Ceilometers in View of Future Integrated Networks in Europe, Bound.Lay. Meteorol., 143, 49-75, https://doi.org/10.1007/s10546-0119643-z, 2011.

Hervo, M., Poltera, Y., and Haefele, A.: An empirical method to correct for temperature-dependent variations in the overlap function of CHM15k ceilometers, Atmos. Meas. Tech., 9, 2947-2959, https://doi.org/10.5194/amt-9-2947-2016, 2016.

Holben, B. N., Eck, T. I., Slutsker, I., Tanré, D., Buis, J. P., Setzer, A., Vermote, E., Reagan, J. A., Kaufman, Y. J., Nakajima, T., Lavenu, F., Jankowiak, I., and Smirnov, A.: AERONET - A Federated Instrument Network and Data Archive for Aerosol Characterization, Remote Sens. Environ., 66, 1-16, 1998.

Illingworth, A., Cimini, D., Haefele, A., Haeffelin, M., Hervo, M., Kotthaus, S., Löhnert, U., Martinet, P., Mattis, I., O'Connor, E., and Potthast, R.: How can Existing Ground-Based Profiling Instruments Improve European Weather Forecasts?, B. Am. Meteorol. Soc., https://doi.org/10.1175/BAMS-D-17-0231.1, online first, 2018.
Jin, Y., Kai, K., Kawai, K., Nagai, T., Sakai, T., Yamazaki, A., Uchiyama, A., Batdorj, D., Sugimoto, N., and Nishizawa, T.: Ceilometer calibration for retrieval of aerosol optical properties, J. Quant. Spectrosc. Ra., 153, 49-56, https://doi.org/10.1016/j.jqsrt.2014.10.009, 2015.

Jones, D. W., Ouldridge, M., and Painting, D. J.: WMO International Ceilometer Intercomparison (United Kingdom, 1986), WMO, Instruments and Oberserving Methods, Report No. 32, Geneva, 1988.

Kaskaoutis, D. G. and Kambezidis, H. D.: Investigation into the wavelength dependence of the aerosol optical depth in the Athens area, Q. J. Roy. Meteor. Soc., 132, 2217-2234, 2006.

Klett, J. D.: Stable analytical inversion solution for processing lidar returns, Appl. Optics, 20, 211-220, 1981.

Kotthaus, S. and Grimmond, C. S. B.: Atmospheric Boundary Layer Characteristics from Ceilometer Measurements Part 1: A new method to track mixed layer height and classify clouds, Q. J. Roy. Meteor. Soc., 144, 1525-1538, https://doi.org/10.1002/qj.3299, 2018a.

Kotthaus, S. and Grimmond, C. S. B.: Atmospheric Boundary Layer Characteristics from Ceilometer Measurements Part 2: Application to London's Urban Boundary Layer, Q. J. Roy. Meteor. Soc., 144, 1511-1524, https://doi.org/10.1002/qj.3298, 2018 b.

Kotthaus, S., O'Connor, E., Münkel, C., Charlton-Perez, C., Haeffelin, M., Gabey, A. M., and Grimmond, C. S. B.: Recommendations for processing atmospheric attenuated backscatter profiles from Vaisala CL31 ceilometers, Atmos. Meas. Tech., 9, 37693791, https://doi.org/10.5194/amt-9-3769-2016, 2016.

Liu, L., Zhang, T., Wu, Y., Wang, Q., and Gao, T.: Accuracy analysis of the aerosol backscatter coefficient profiles derived from the CYY-2B ceilometer, Adv. Meteorol., 2018, 9738197, https://doi.org/10.1155/2018/9738197, 2018.

Lotteraner, C. and Piringer, M.: Mixing-Height Time Series from Operational Ceilometer Aerosol-Layer Heights, Bound.-Lay. Meteorol., 161, 265-287, https://doi.org/10.1007/s10546-0160169-2, 2016.

Madonna, F., Amato, F., Vande Hey, J., and Pappalardo, G.: Ceilometer aerosol profiling versus Raman lidar in the frame of the INTERACT campaign of ACTRIS, Atmos. Meas. Tech., 8, 2207-2223, https://doi.org/10.5194/amt-8-2207-2015, 2015.

Madonna, F., Rosoldi, M., Lolli, S., Amato, F., Vande Hey, J., Dhillon, R., Zheng, Y., Brettle, M., and Pappalardo, G.: Intercomparison of aerosol measurements performed with multiwavelength Raman lidars, automatic lidars and ceilometers in the framework of INTERACT-II campaign, Atmos. Meas. Tech., 11, 2459-2475, https://doi.org/10.5194/amt-11-2459-2018, 2018.

Markowicz, K. M., Flatau, P. J., Kardas, A. E., Remiszewska, J., Stelmaszczyk, K., and Woeste, L.: Ceilometer Retrieval of the Boundary Layer Vertical Aerosol Extinction Structure, J. Atmos. Ocean. Tech., 25, 928-944, 2008.

Münkel, C., Eresmaa, N., Räsänen, J., and Karppinen, A.: Retrieval of mixing height and dust concentration with lidar ceilometer, Bound.-Lay. Meteorol., 124, 117-128, 2007.

Pappalardo, G., Amodeo, A., Apituley, A., Comeron, A., Freudenthaler, V., Linné, H., Ansmann, A., Bösenberg, J., D’Amico, G., Mattis, I., Mona, L., Wandinger, U., Amiridis, V., AladosArboledas, L., Nicolae, D., and Wiegner, M.: EARLINET: towards an advanced sustainable European aerosol lidar network, 
Atmos. Meas. Tech., 7, 2389-2409, https://doi.org/10.5194/amt7-2389-2014, 2014.

Pattantyús-Ábrahám, M., Mattis, I., Begbie, R., Bravo-Aranda, J. A., Brettle, M., Cermak, J., Drouin, M.-A., Geiß, A., Görsdorf, U., Haefele, A., Haeffelin, M., Hervo, M., Komínková, K., Leinweber, R., Münkel, C., Pönitz, K., Vande Hey, J., Wagner, F., and Wiegner, M.: The Dataset of the CeiLinEx2015 Ceilometer-Inter-comparison Experiment, Version v001, https://doi.org/10.5676/DWD/CEILINEX2015, 2017.

Román, R., Benavent-Oltra, J. A., Casquero-Vera, J. A., Lopatin, A., Cazorla, A., Lyamani, H., Denjean, C., Fuertes, D., PérezRamírez, D., Torres, B., Toledano, C., Dubovik, O., Cachorro, V. E., de Frutos, A. M., Olmo, F. J., and Alados-Arboledas, L.: Retrieval of aerosol profiles combining sunphotometer and ceilometer measurements in GRASP code, Atmos. Res., 204, 161-177, https://doi.org/10.1016/j.atmosres.2018.01.021, 2018.

Schäfer, K., Thomas, W., Peters, A., Ries, L., Obleitner, F., Schnelle-Kreis, J., Birmili, W., Diemer, J., Fricke, W., Junkermann, W., Pitz, M., Emeis, S., Forkel, R., Suppan, P., Flentje, H., Gilge, S., Wichmann, H. E., Meinhardt, F., Zimmermann, R., Weinhold, K., Soentgen, J., Münkel, C., Freuer, C., and Cyrys, J.: Influences of the 2010 Eyjafjallajökull volcanic plume on air quality in the northern Alpine region, Atmos. Chem. Phys., 11, 8555-8575, https://doi.org/10.5194/acp-11-8555-2011, 2011.

Schuster, G. L., Dubovik, O., and Holben, B. N.: Angstrom exponent and bimodal aerosol size distributions, J. Geophys. Res., 111, D07207, https://doi.org/10.1029/2005JD006328, 2006.
Sundström, A. M., Nousiainen, T., and Petäjä, T.: On the Quantitative Low-Level Aerosol Measurements Using Ceilometer-Type Lidar, J. Atmos. Ocean. Tech., 26, 2340 2352, https://doi.org/10.1175/2009JTECHA1252.1, 2009.

Warren, E., Charlton-Perez, C., Kotthaus, S., Lean, H., Ballard, S., Hopkin, E., and Grimmond, S.: Evaluation of forward-modelled attenuated backscatter using an urban ceilometer network in London under clear-sky conditions, Atmos. Environ., 191, 532-547, https://doi.org/10.1016/j.atmosenv.2018.04.045, 2018.

Wiegner, M. and Gasteiger, J.: Correction of water vapor absorption for aerosol remote sensing with ceilometers, Atmos. Meas. Tech., 8, 3971-3984, https://doi.org/10.5194/amt-8-3971-2015, 2015.

Wiegner, M. and Geiß, A.: Aerosol profiling with the Jenoptik ceilometer CHM15kx, Atmos. Meas. Tech., 5, 1953-1964, https://doi.org/10.5194/amt-5-1953-2012, 2012.

Wiegner, M., Gasteiger, J., Groß, S., Schnell, F., Freudenthaler, V., and Forkel, R.: Characterization of the Eyjafjallajökull ashplume: Potential of lidar remote sensing, Phys. Chem. Earth, 4546, 79-86, https://doi.org/10.1016/j.pce.2011.01.006, 2012.

Wiegner, M., Madonna, F., Binietoglou, I., Forkel, R., Gasteiger, J., Geiß, A., Pappalardo, G., Schäfer, K., and Thomas, W.: What is the benefit of ceilometers for aerosol remote sensing? An answer from EARLINET, Atmos. Meas. Tech., 7, 1979-1997, https://doi.org/10.5194/amt-7-1979-2014, 2014. 